This is an electronic reprint of the original article. This reprint may differ from the original in pagination and typographic detail.

\author{
Author(s): Buades, Ana B.; Arderiu, Victor Sanchez; Olid-Britos, David; Viñas, Clara; Sillanpää, \\ Reijo; Haukka, Matti; Fontrodona, Xavier; Paradinas, Marcos; Ocal, Carmen; Teixidor, \\ Francesc
}

Title: $\quad$ Electron accumulative molecules

Year: $\quad 2018$

Version:

Please cite the original version:

Buades, A. B., Arderiu, V. S., Olid-Britos, D., Viñas, C., Sillanpää, R., Haukka, M., Fontrodona, X., Paradinas, M., Ocal, C., \& Teixidor, F. (2018). Electron accumulative molecules. Journal of the American Chemical Society, 140(8), 2957-2970. https://doi.org/10.1021/jacs.7b12815

All material supplied via JYX is protected by copyright and other intellectual property rights, and duplication or sale of all or part of any of the repository collections is not permitted, except that material may be duplicated by you for your research use or educational purposes in electronic or print form. You must obtain permission for any other use. Electronic or print copies may not be offered, whether for sale or otherwise to anyone who is not an authorised user. 


\section{Article}

\section{Electron accumulative molecules}

Ana B. Buades, Victor Sanchez Arderiu, David Olid-Britos, Clara Viñas, Reijo Sillanpää, Matti Haukka, Xavier Fontrodona, Marcos Paradinas, Carmen Ocal, and Francesc Teixidor

J. Am. Chem. Soc., Just Accepted Manuscript • DOI: 10.1021/jacs.7b12815 • Publication Date (Web): 03 Feb 2018

Downloaded from http://pubs.acs.org on February 5, 2018

\section{Just Accepted}

"Just Accepted" manuscripts have been peer-reviewed and accepted for publication. They are posted online prior to technical editing, formatting for publication and author proofing. The American Chemical Society provides "Just Accepted" as a service to the research community to expedite the dissemination of scientific material as soon as possible after acceptance. "Just Accepted" manuscripts appear in full in PDF format accompanied by an HTML abstract. "Just Accepted" manuscripts have been fully peer reviewed, but should not be considered the official version of record. They are citable by the Digital Object Identifier (DOI@). "Just Accepted" is an optional service offered to authors. Therefore, the "Just Accepted" Web site may not include all articles that will be published in the journal. After a manuscript is technically edited and formatted, it will be removed from the "Just Accepted" Web site and published as an ASAP article. Note that technical editing may introduce minor changes to the manuscript text and/or graphics which could affect content, and all legal disclaimers and ethical guidelines that apply to the journal pertain. ACS cannot be held responsible for errors or consequences arising from the use of information contained in these "Just Accepted" manuscripts. 


\title{
Electron accumulative molecules
}

\author{
Ana B. Buades, ${ }^{\mathrm{a}}$ Víctor Sanchez Arderiu, ${ }^{\mathrm{a}}$ David Olid-Britos, ${ }^{\mathrm{a}}$ Clara Viñas, ${ }^{\mathrm{a}}$ Reijo \\ Sillanpää, ${ }^{\mathrm{b}}$ Matti Haukka, ${ }^{\mathrm{b}}$ Xavier Fontrodona, ${ }^{\mathrm{c}}$ Marcos Paradinas, ${ }^{\mathrm{a}} \mathrm{Carmen}_{\mathrm{Ocal}}{ }^{\mathrm{a}}$ and \\ Francesc Teixidor ${ }^{\mathrm{a}, *}$ \\ a. Institut de Ciència de Materials de Barcelona (ICMAB-CSIC). Campus UAB, 08193 Bellaterra, \\ Barcelona, Spain. \\ b. Dept. of Chemistry, University of Jyväskylä. FIN-40014, Jyvaskyla, Finland. \\ c. Dept. de Química and Serveis Tècnics de Recerca, Universitat de Girona, Campus de Montilivi, E- \\ 17071 Girona, Spain.
}

Corresponding autor: teixidor@icmab.es

\begin{abstract}
With the goal to produce molecules with high electron accepting capacity and low reorganization energy upon gaining one or more electrons, a synthesis procedure leading to the formation of a B-N(aromatic) bond in a cluster has been developed. The research was focused on the development of a molecular structure able to accept and release a specific number of electrons without decomposing or change in their structural arrangements. The synthetic procedure consists of a parallel decomposition reaction to generate a reactive electrophile and a synthesis reaction to generate the $\mathrm{B}-\mathrm{N}$ (aromatic) bond. This procedure has paved the way to produce the metallacarboranylviologen $\left[\mathrm{M}\left(\mathrm{C}_{2} \mathrm{~B}_{9} \mathrm{H}_{11}\right)\left(\mathrm{C}_{2} \mathrm{~B}_{9} \mathrm{H}_{10}\right)-\mathrm{NC}_{5} \mathrm{H}_{4}-\mathrm{C}_{5} \mathrm{H}_{4} \mathrm{~N}-\mathrm{M}^{\prime}\left(\mathrm{C}_{2} \mathrm{~B}_{9} \mathrm{H}_{11}\right)\left(\mathrm{C}_{2} \mathrm{~B}_{9} \mathrm{H}_{10}\right)\right] \quad\left(\mathrm{M}=\mathrm{M}^{\prime}=\mathrm{Co}\right.$, Fe and $\mathrm{M}=\mathrm{Co}$ and $\left.\mathrm{M}^{\prime}=\mathrm{Fe}\right)$ and semi(metallacarboranyl)viologen $\quad\left[3,3^{\prime}-\mathrm{M}\left(8-\left(\mathrm{NC}_{5} \mathrm{H}_{4}-\mathrm{C}_{5} \mathrm{H}_{4} \mathrm{~N}-1,2-\mathrm{C}_{2} \mathrm{~B}_{9} \mathrm{H}_{10}\right)\left(1^{\prime}, 2^{\prime}-\mathrm{C}_{2} \mathrm{~B}_{9} \mathrm{H}_{11}\right)\right] \quad(\mathrm{M}=\mathrm{Co}\right.$, $\mathrm{Fe})$ electron cumulative molecules. These molecules are able to accept up to five electrons and to donate one in single electron steps at accessible potentials and in a reversible way. By targeted synthesis and corresponding electrochemical tests each Electron Transfer (ET) step has been assigned to specific fragments of the molecules. The molecules have been carefully characterized and the electronic communication between both metal centers (when this situation applies) has been definitely observed through the co-planarity of both pyridine fragments. The structural characteristics of these molecules imply a low reorganization energy that is a necessary requirement for low energy ET processes. This makes them electronically comparable to fullerenes, but on their side they have a wide range of possible solvents. The ET from one molecule to another has been clearly demonstrated as well as their self-organizing capacity. We consider that these molecules thanks to their easy synthesis, ET, self-organizing capacity, wide range of solubility and easy processability can find important application in any area where ET is paramount.
\end{abstract}




\section{Introduction}

Molecules with dimensions of few nanometers that can store a high number of electrons find important applications for the design of devices able to perform complex functions, as in molecular switches, ${ }^{1}$ receptors, ${ }^{2}$ photoconductors and photoactive dyads. ${ }^{3}$ These applications are generally based on their excellent electron accepting properties along with low reorganization energy. ${ }^{4}$ Typical examples are $\mathrm{C}_{60}$ with a van Der Waals diameter about $1.1 \mathrm{~nm}$ and capability of accepting up to six electrons, four of them in reversible one-electron reduction steps according to Cyclic Voltammetry (CV). ${ }^{5-7}$ Other examples are polyoxometallates (POMs) that are combinations between oxygen and early transition metals at their highest oxidation states, and usually contain a variety of heteroatoms such as P, As, Si, Ge, or others. ${ }^{8-9}$ In this context, one of the most significant properties of POMs is the ability of many of them to accept and release a specific number of electrons without decomposing or change in their structural arrangements. ${ }^{10}$ One recent example is the cluster $\left[\mathrm{W}_{18} \mathrm{O}_{54}\left(\mathrm{SeO}_{3}\right)_{2}\right]^{4-}$ that can be reduced multiple times and the two Se dopants can be oxidized. This cluster has also a nanoscale size (about $1.2 \times 1 \times 1 \mathrm{~nm}) .{ }^{10}$ Thus, both type of molecules, fullerenes and polyoxometallates, have nanometer dimensions, have excellent electron accepting properties and low reorganization energy upon the capture or release of one electron, and find wide application in molecular electronics; ${ }^{11-12}$ however, these remarkable properties are opposed to the ease of functionalization while keeping the genuine physical characteristics of the pristine compounds; additionally, the pristine molecules are difficult to be processed thus complicating their practical use.

Metallacarborane sandwich compounds contain one or more carborane fragment ligands. ${ }^{13}$ The more popular and more stable, thence the best studied is metallabisdicarbollide, $\left[3,3^{\prime}-\mathrm{M}\left(1,2-\mathrm{C}_{2} \mathrm{~B}_{9} \mathrm{H}_{11}\right)_{2}\right]^{-}(\mathrm{M}=$ Co, [1] ; Fe, [2]- (Figure 1). ${ }^{14-16}$ They have a non-localized negative charge spread all over the molecule,${ }^{17}$ have a relatively low symmetry that results in many non-equivalences among the boron atoms, and obviously between these and the carbon atoms, and have many possibilities to produce hydrogen bonds, e.g. $\mathrm{C}_{\mathrm{c}}-\mathrm{H} \cdots \mathrm{O}$ and dihydrogen bonding $\mathrm{C}_{\mathrm{c}}-\mathrm{H} \cdots \mathrm{H}-\mathrm{B}$, in which $\mathrm{C}_{\mathrm{c}}$ stands for the cluster carbon atoms. The latter are proven to participate in their self-assembling. ${ }^{18}$ Further, they can be solubilized either in water or in organic solvents, depending on the cation. ${ }^{19-20}$ These characteristics are unique, rarely encountered in other redox reversible organic and organometallic complexes.

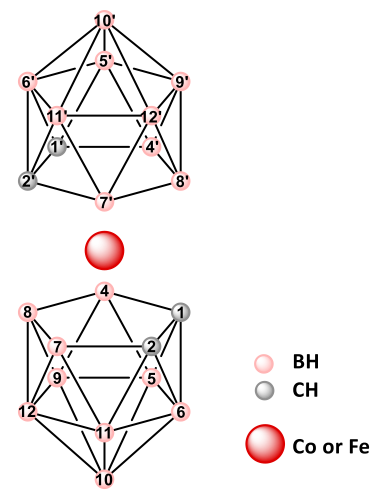

Figure 1. Molecular structure of metallacarboranes: $[1]^{-}(\mathrm{M}=\mathrm{Co})$ and $[2]^{-}(\mathrm{M}=\mathrm{Fe})$.

Cobaltabisdicarbollide, [1] $]^{-}$, has three accessible redox reversible processes, ${ }^{14-16,}{ }^{21}$ formally $\mathrm{Co}^{2+/+}$, $\mathrm{Co}^{3+/ 2+}$ and $\mathrm{Co}^{4+/ 3+}$ at $-2.64 \mathrm{~V},-1.75 \mathrm{~V}$ and $1.22 \mathrm{~V}$, respectively $v s \mathrm{Fc}$, although the $\mathrm{Co}^{3+/ 2+}$ is the one more readily observed and studied. ${ }^{22}$ Thanks to the relatively low symmetry of the metallacarborane, the boron content of the molecule and the tridimensional aromaticity of the cluster, ${ }^{23}$ this framework 
performs uniquely in the sense that a regular stepwise modulation of $E_{1 / 2}$ is possible, thus allowing for controlled $\mathrm{E}^{1 / 2}$ potentials that can be tailored for specific purposes. ${ }^{24-25}$

The characteristics of metallacarboranes led us to consider the possibility of producing metallacarborane containing molecules that could accumulate several electrons in the different molecular moieties ${ }^{21}$ that would also show electronic communication, that the electron-acceptor capacity could be easily tuned, with a strong self-assembling capacity, with low reorganization energy and showing easy processability. To get the metallacarboranes' interrelation/electronic communication it was necessary to link two metallacarborane clusters via an unsaturated bridge. The linker with the desired profile was 4,4'-bipyridine that would lead to the bipyridinium unit. This 4,4'-bipyridine bridged, when terminated with methyl groups is the well-known methylviologen, $\mathrm{MV}$, that is able to change colour reversibly upon reduction and oxidation, ${ }^{26-27}$ and is a well-known electron acceptor. In this work we present results that show that the departure points are real, and that up to five electrons have been accumulated reversibly in a molecule in $\mathrm{CV}$ conditions.

\section{Results and discussion}

\section{Synthesis}

Very few reports exist on the formation of B-N bonds on cobaltabisdicarbollide ${ }^{28-34}$ but no one in which the $\mathrm{N}$ is part of an aromatic ring. This would require overcoming an age-old challenge we had and that we have solved as described below. Metallacarboranes have two definitely distinct element binding sites, $\mathrm{C}$ and $\mathrm{B}$ in their structure. Our and others recent studies on stepwise $\mathrm{E}_{1 / 2}$ tuning in cobaltabisdicarbollide derivatives have demonstrated that boron substitution leads to an appealingly large range of distinct $\mathrm{E}_{\frac{1}{2} / 2}$ values, in parallel to the number of boron substitutions. ${ }^{35-36}$ This, along with the electronegativity value of boron $\mathrm{X}_{\mathrm{B}}=2.04$ that resembles more these of late transition metals than the one of its neighbor $\mathrm{C}, \mathrm{X}_{\mathrm{C}}=2.55$, motivated us to find ways to produce $\mathrm{B}-\mathrm{N}$ bonds to ultimately produce (metallacarboranyl)viologen. Our prospective attempts were done with pyridine. A procedure based on the attack of a nucleophile to the iodonium bridged cobaltabisdicarbollide was available to generate $\mathrm{B}-\mathrm{N}$ (aromatic) bonds. If the nucleophile was pyridine it could lead to the pyridinium derivative of $\left[3,3^{\prime}-\mathrm{Co}\left(1,2-\mathrm{C}_{2} \mathrm{~B}_{9} \mathrm{H}_{11}\right)_{2}\right]^{-}\left([\mathbf{1}]^{-}\right)$in which the iodo group would remain in the compound. ${ }^{30}$ The initial efforts to produce B-N bonds were to explore the use of the readily available Cs[3,3'$\left.\mathrm{Co}\left(1,2-\mathrm{C}_{2} \mathrm{~B}_{9} \mathrm{H}_{11}\right)_{2}\right], \mathrm{Cs}[\mathbf{1}]$, as starting reagent. To this purpose the $\mathrm{Cs}[\mathbf{1}]$ was reacted with pyridine in diverse conditions of temperature and absence or presence of solvent, however in all cases [1] $]^{-}$was left intact, and no hints of improving this result were observed by modifying the reaction conditions. Then it was considered to explore a new procedure starting with $\mathrm{Cs}\left[3,3\right.$ ' $\left.-\mathrm{Co}\left(8-\mathrm{I}-1,2-\mathrm{C}_{2} \mathrm{~B}_{9} \mathrm{H}_{10}\right)\left(1,2-\mathrm{C}_{2} \mathrm{~B}_{9} \mathrm{H}_{11}\right)\right]$, $\mathrm{Cs}[3] .{ }^{37}$ Briefly, the procedure consists in mixing the Cesium salt of [3] $]^{-}$with pyridine that behaves as reagent and as solvent. The reaction is carried out in a Pyrex sealed tube in an oven at $200^{\circ} \mathrm{C}$ for $16 \mathrm{~h}$. The procedure was successful and after workup, led to the sought pyridinium derivative $\mathbf{5}$ in $70 \%$ yield. The reaction consists of a parallel decomposition reaction to generate a reactive electrophile that reacts with pyridine generating the B-N bond (Scheme 1). The crystal structure of 5 is shown in Figure $2 .{ }^{38}$ 


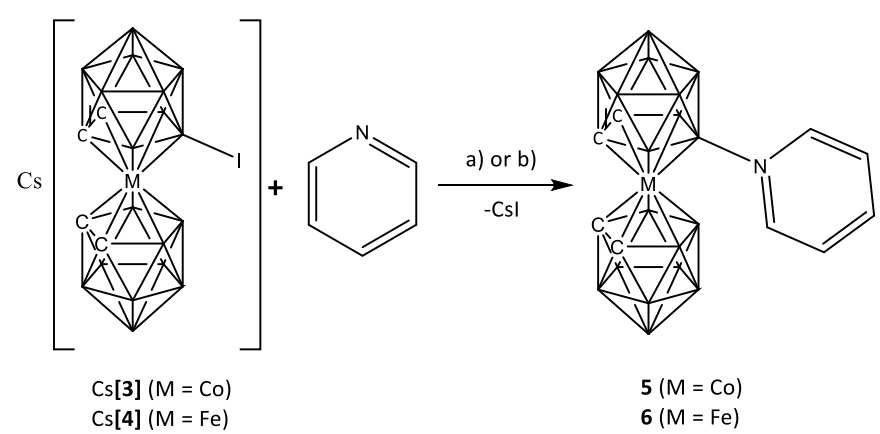

Scheme 1. Reaction conditions for the synthesis of compounds 5 and $\mathbf{6}$ under dry conditions. a) For M=Co, sealed tube, $200^{\circ} \mathrm{C}, 16 \mathrm{~h}$, vacuum. b) For $\mathrm{M}=\mathrm{Fe}$, toluene, $110^{\circ} \mathrm{C}, 4$ days.

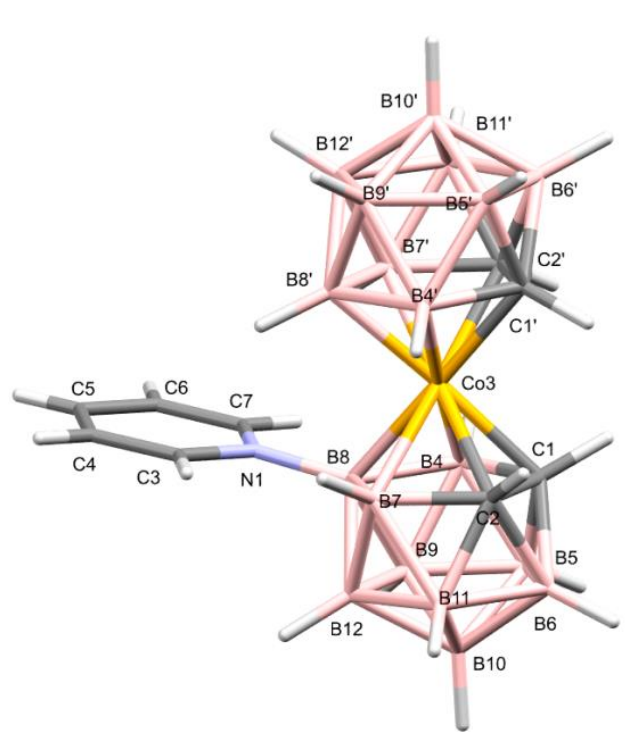

a)

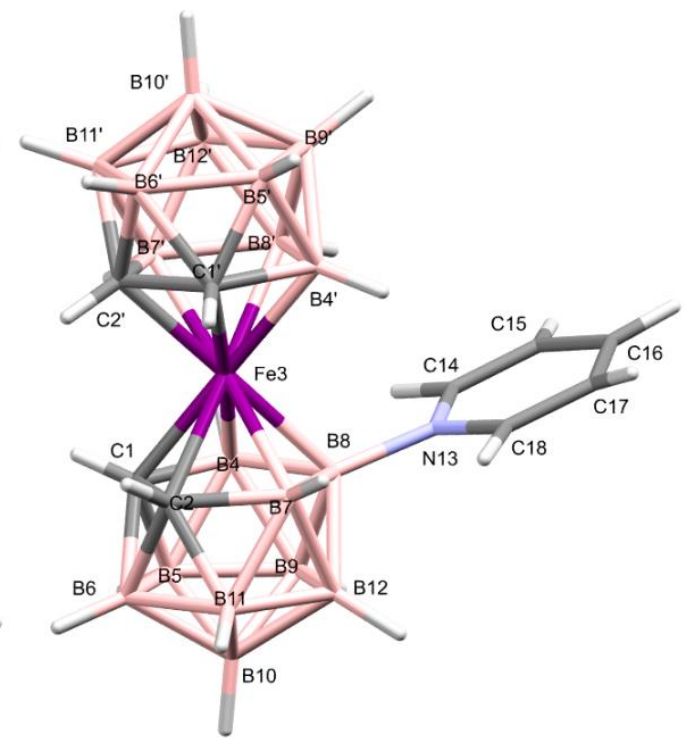

b)

Figure 2. Crystal structures of compounds 5 (a) and 6 (b).

This procedure was unapplicable when starting with $\mathrm{Cs}\left[3,3^{\prime}\right.$ - $\left.\mathrm{Fe}\left(8-\mathrm{I}-1,2-\mathrm{C}_{2} \mathrm{~B}_{9} \mathrm{H}_{10}\right)\left(1,2-\mathrm{C}_{2} \mathrm{~B}_{9} \mathrm{H}_{11}\right)\right]$, $\mathrm{Cs}[4]^{21}$ to achieve compound 6. In this case, a less harsh method was needed. It consists in mixing $\mathrm{Cs}[4]$, excess pyridine in dry toluene as solvent and in refluxing conditions for 4 days. (Scheme 1). The molecular structure of $\mathbf{6}$ is shown in Figure $2 .{ }^{39}$ Following similar synthetic strategies for Co and $\mathrm{Fe}$ as these used for $\mathbf{5}$ and $\mathbf{6}$, we proceeded with the synthesis of the Co and $\mathrm{Fe}$ semi(metallacarboranyl)viologen. In these cases, 4,4'-bipyridine was used instead of pyridine to achieve the semi(metallacarboranyl)viologen compounds $\mathbf{7}$ and $\mathbf{8}$. We have named them "semi" because only one of the two $\mathrm{N}$ atoms is involved in the binding of the 4,4'-bipyridine with the metallacarborane, as opposed to the 11, 12 and 13 molecules in which both bipyridine nitrogen atoms are linked to metallacarboranes; these molecules plainly will be named di(metallacarboranyl)viologen (Scheme 2).

To generate the semi(cobaltabisdicarboranyl)viologen 7, in solvent free conditions, a 4-fold excess of 4,4'-bipyridine was mixed with $\mathrm{Cs}[3]$ in a pyrex tube that was subsequently sealed in vacuum, then introduced in an oven at $200^{\circ} \mathrm{C}$ for $16 \mathrm{~h}$. After workup, the isolated yield of the compound was $71 \%$ (Scheme 2a). As for $\mathbf{6}$, this procedure could not be used to synthesize the iron analogue compound $\mathbf{8}$. The conditions are too harsh and the cluster suffers degradation. Applying also a 3-fold excess of 4,4'- 
bipyridine the dry toluene procedure used for $\mathbf{6}$ was applied producing $\mathbf{8}$ with a yield of $65 \%$ (Scheme 2b).

Both cobalt (7) and iron (8) semi(metallacarboranyl)viologens are adequate starting wildcard reagents to generate challenging compounds that will be the object of future research. The simplest one is the $\mathrm{N}$ metallacarboranyl-N'-methylviologen iodide [9]I and [10]I shown in Scheme 2 that, as methylviologen $[\mathrm{MV}]^{2+}$, is a dicationic salt, although in this case overall is monocationic. Also, starting from the adequate semi(metallacarboranyl)viologen and upon reaction with $\mathrm{Cs}[3]$ or $\mathrm{Cs}[4]$ in the four days refluxing dry toluene protocol the homodi(metallacarboranyl)viologen compounds $\mathrm{CoCo}-(\mathbf{1 1})$, FeFe- (12) or the $\mathrm{CoFe}-$ heterodi(metallacarboranyl)viologen (13) can be produced (Scheme $2 \mathrm{c}, \mathrm{d}, \mathrm{e}$ ). However, as it is a two stages reaction that implies the isolation and purification of the intermediate semi(metallacarboranyl)viologen the refluxing toluene protocol is only practical, and the only possibility, for the CoFe-heterodi(metallacarboranyl)viologen (13) and $\mathrm{FeFe}$ homodi(metallacarboranyl)viologen (12). When CoCo-homodi(metallacarboranyl)viologen (11) is synthesized the protocol utilized is the one with a sealed tube, starting from the bare reagents, $\operatorname{Cs}[3]$ and 4,4'-bipyridine in 2:1 ratios, at the oven at $200^{\circ} \mathrm{C}$, and utilizing naphthalene as a solvent; conversely when FeFe- (12) is sought, the dry toluene protocol extended to 4 days of refluxing dry toluene, also from the bare $\mathrm{Cs}[4]$ and 4,4'-bipyridine in $2: 1$ ratios, is the one utilized. The reaction to produce the homodi(metallacarboranyl)viologen is depicted in Scheme $2 \mathrm{c}$ and $2 \mathrm{~d}$.

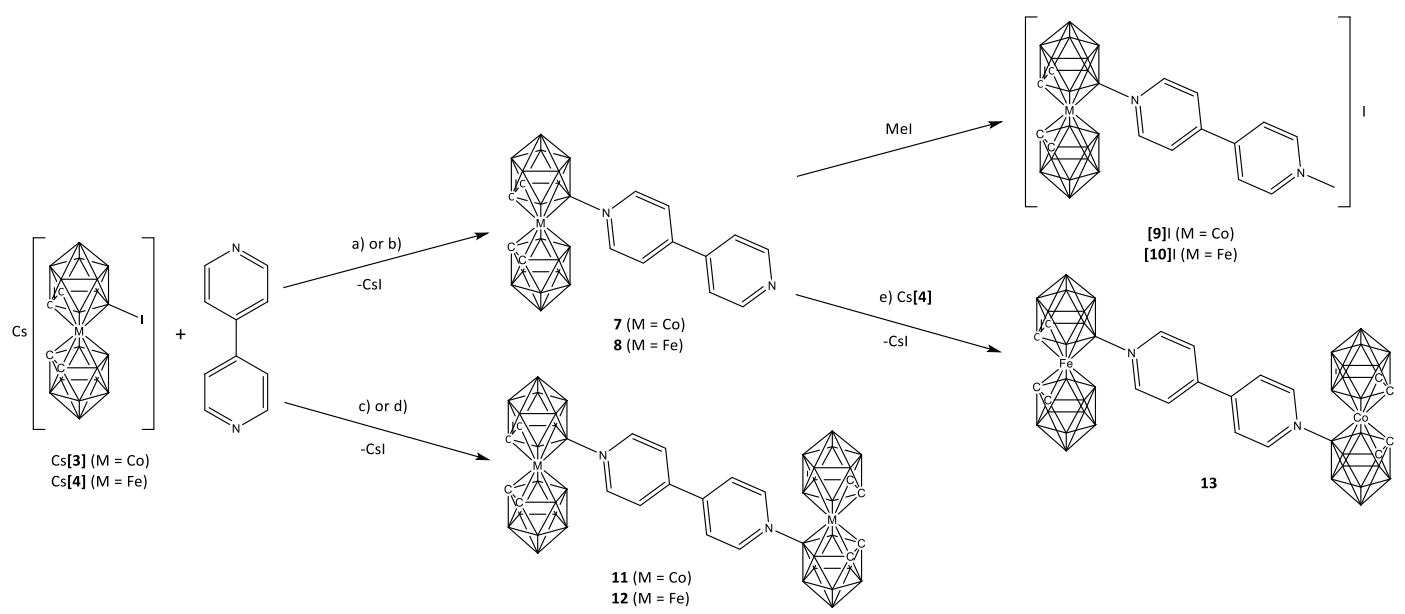

Scheme 2. Reaction conditions for the synthesis of compounds 7, 8, [9]I, [10]I, 11, 12 and 13. a )For 7, 4-fold excess of 4,4'-bipyridine, sealed tube, $200^{\circ} \mathrm{C}, 16 \mathrm{~h}$, vacuum. b) For $\mathbf{8}, 3$-fold excess of $4,4^{\prime}$-bipyridine, dry toluene $110^{\circ} \mathrm{C}, 4$ days. c) For 11, 2-fold excess of $\mathrm{Cs}\left[3\right.$ ], sealed tube, $200^{\circ} \mathrm{C}, 16 \mathrm{~h}$, naphthalene and vacuum. d) For 12, 2-fold excess of $\mathrm{Cs}[\mathbf{4}]$, toluene, $110^{\circ} \mathrm{C}, 4$ days. e) For 13 , starting with compound 7, then $\mathrm{Cs}[\mathbf{4}]$, toluene, $110^{\circ} \mathrm{C}, 4$ days.

\section{Characterization}

All these molecules (5-13) have been characterized by ${ }^{1} \mathrm{H}-,{ }^{1} \mathrm{H}\left\{{ }^{11} \mathrm{~B}\right\}-,{ }^{13} \mathrm{C}\left\{{ }^{1} \mathrm{H}\right\}-,{ }^{11} \mathrm{~B}$ - and ${ }^{11} \mathrm{~B}-\left\{{ }^{1} \mathrm{H}\right\}-$ NMR, EA and for the cases of 5, 6, 7, 8 and 11, 12 by X-ray diffraction. ${ }^{40}$ All spectral information can be found in the S.I.

The ${ }^{1} \mathrm{H}$ - and ${ }^{1} \mathrm{H}\left\{{ }^{11} \mathrm{~B}\right\}$-NMR spectra were key for the Cobalt derivatives to confirm the structure of the compounds. The semi(cobaltabisdicarboranyl)viologen 7 presents 4 different signals for the aromatic protons of the bipyridine core ( 2 for the substituted pyridine and 2 for the non-substituted), while the 
CoCo-di(metallacarboranyl)viologen, 11, only shows 2 signals due to the higher symmetry of the molecule (Figure 3). Moreover, the single crystal X-ray diffraction of both compounds confirmed the NMR results.

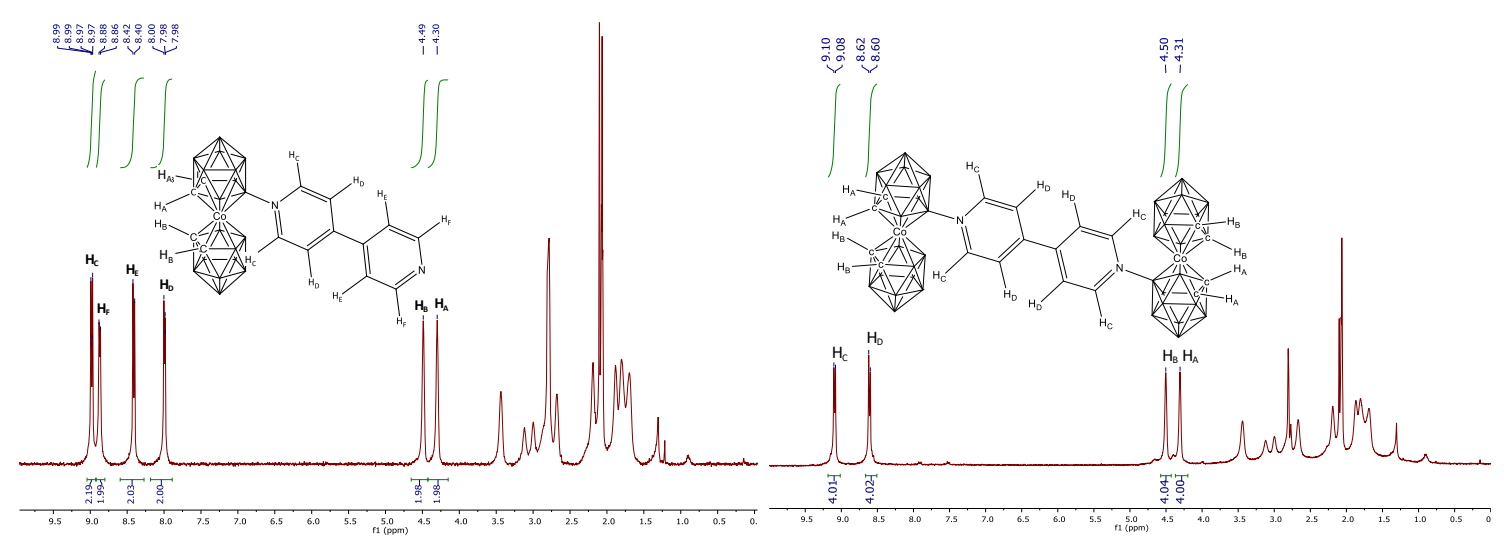

Figure 3. ${ }^{1} \mathrm{H}\left\{{ }^{11} \mathrm{~B}\right\}$-NMR comparison and proton assignment of compounds $\mathbf{7}$ and $\mathbf{1 1 .}$

Suitable single crystals of cobalt compounds 5, 7 and 11 were obtained by slow evaporation of the solvent from solutions of acetonitrile, acetone and tetrahydrofuran, respectively. And the iron compounds 6,8 and 12 were obtained by slow diffusion of solution compounds in acetonitrile through silica gel (See S.I.). ${ }^{41}$ The X-ray structures are presented in Figures 2, 4 and 5, and the crystallographic data is given in the S. I.

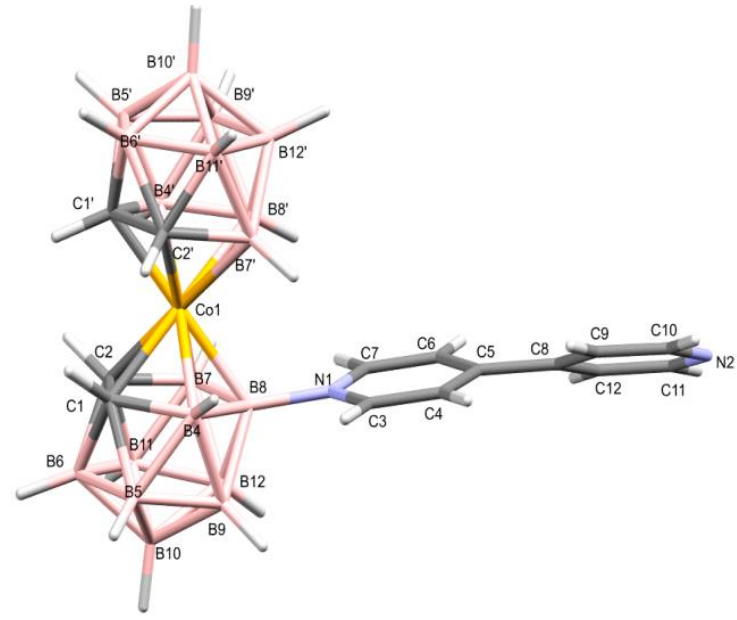

a)

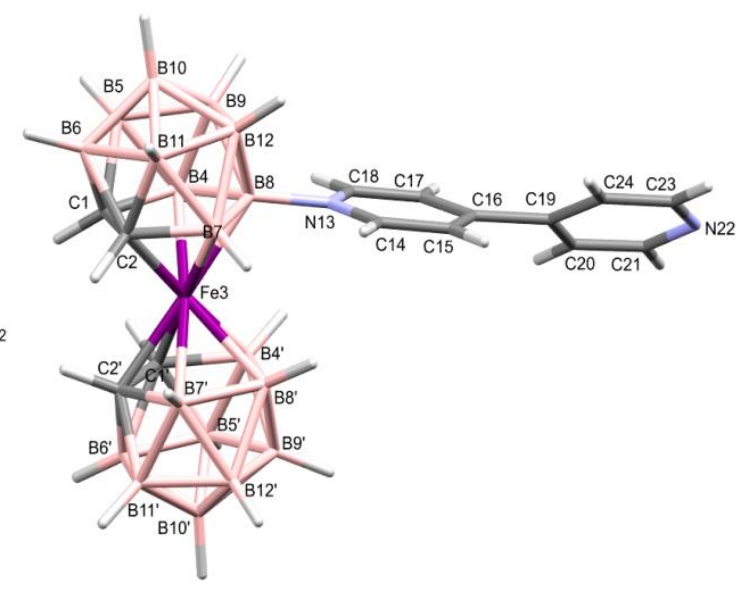

b)

Figure 4. Crystal structure of compounds 7 and 8. a) The asymmetric unit of $\mathbf{7}$ and $\mathbf{8}$ contains two independent molecules. Selected lengths $(\AA)$ and angles $\left({ }^{\circ}\right)$ : $\mathrm{C}(1)-\mathrm{C}(2)$ 1.612(4), $\mathrm{C}\left(1^{\prime}\right)-\mathrm{C}\left(2^{\prime}\right)$ 1.618(5), B(8)-N(1) 1.549(4). Dihedral angle between $\mathrm{C}(6)-\mathrm{C}(5)-\mathrm{C}(8)-\mathrm{C}(12)-20.3(5), \mathrm{C}(6 \mathrm{~B})-\mathrm{C}(5 \mathrm{~B})-\mathrm{C}(8 \mathrm{~B})-\mathrm{C}(12 \mathrm{~B})$ 26.3(5). b) For compound 8, selected lengths $(\AA)$ and angles $\left(^{\circ}\right)$ : $\mathrm{C}(1)-\mathrm{C}(2)$ 1.612(4), $\mathrm{C}\left(1^{\prime}\right)-\mathrm{C}\left(2^{\prime}\right)$ 1.613(6), $\mathrm{B}(8)-\mathrm{N}(13)$ 1.551(5). Dihedral angle between $\mathrm{C}(15)-\mathrm{C}(16)-\mathrm{C}(19)-\mathrm{C}(24)-32.09(6)$.

Basic parameters of the molecular structures of compounds 5, 7 and $\mathbf{1 1}$ are similar and resemble closely the other known cobalt metallabisdicarboranes with substituents at the $\mathrm{B}(8)$ position. ${ }^{42-44}$ However, any other known structures contain carbon or oxygen substituents. A search at the Cambridge Structural Database ${ }^{45}$ shows just eight hits (seven for cobaltabisdicarboranes ${ }^{46}$ and one for ferrabisdicarborane ${ }^{47}$ ) with direct boron nitrogen (non-aromatic) bonds. The average Co-B and Co-C distances in compounds $\mathbf{5}, 7$ and 11 range from 2.037(3)-2.111(3) $\AA$ and 2.087-2.127(4) $\AA$, respectively. For the B-N bond lengths are 1.556(5) $\mathrm{A}, 1.545(4) \AA, 1.549(4), 1.545(4) \AA$ (compounds 
5, 7 and 11 (two independent molecules), respectively). The average Fe-B and Fe-C distances in 6, 8 and 12 range from 2.061(4)-2.109(4) $\AA$ and 2.107(3)-2.161(3) $\AA$ and the B-N bond distance for the three compounds are 1.553 (5) $\AA, 1.552(5) \AA$ and 1.580(13) $\AA$ respectively. The distances are larger for cobalt compounds than the corresponding iron ones.

Comparing the cobalt and iron compounds, it is observed that the structures are very similar except for 11 and 12. In structure 11, the 4,4'-bipyridine is a bridge between two cobaltabisdicarbollide moieties, in which there is a centre of inversion in the middle of the $\mathrm{C}-\mathrm{C}$ connecting the two pyridine moieties.

Due to the centre of symmetry the pyridyl rings are co-planar; this anticipates that there will be electronic communication between the two cobaltabisdicarbollides. Conversely, in 12, the 4,4'bipyridine that also bridges the two ferrabisdicarbollide moieties, does not have any symmetry operation as the dihedral angle between the pyridines is $24^{\circ}$; this anticipates that the electronic communication between the two ferrabisdicarbollides will be partially restricted.
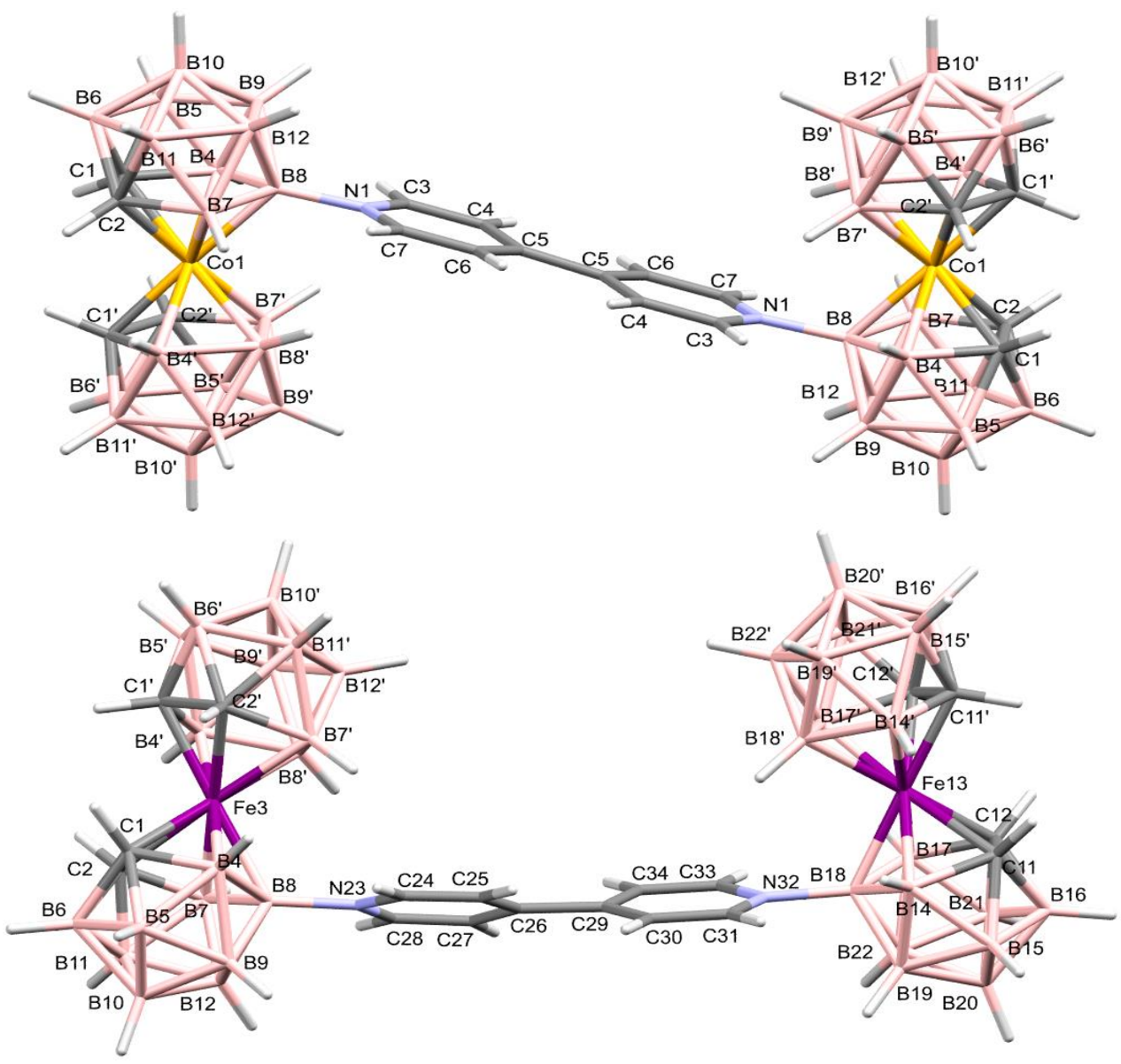

Figure 5. Crystal structure of compounds 11 and 12, a) for compound 11, selected lengths $(\AA)$ and angles $\left(^{\circ}\right)$ : C(1)$\mathrm{C}(2)$ 1.613(5), $\mathrm{C}\left(1^{\prime}\right)-\mathrm{C}\left(2^{\prime}\right)$ 1.612(6), B(8)-N(1) 1.551(5). Dihedral angle between $\mathrm{C}(4)-\mathrm{C}(5)-\mathrm{C}(5)-\mathrm{C}(6)-0.1(6)$. b) for compound 12, selected lengths $(\AA)$ and angles $\left({ }^{\circ}\right)$ : $\mathrm{C}(1)-\mathrm{C}(2) 1.598(13), \mathrm{C}\left(1^{\prime}\right)-\mathrm{C}\left(2^{\prime}\right) 1.582(14), \mathrm{B}(8)-\mathrm{N}(23) 1.559(12)$. Dihedral angle between $\mathrm{C}(25)-\mathrm{C}(26)-\mathrm{C}(29)-\mathrm{C}(30) 22.4(9)$.

In structure 5, the structural units are closely packed with no available voids for solvent molecules. The neighboring molecules are held together mainly by the weak van Der Waals type interactions (Figure $6)$. 
Figure 6. Packing of $\mathbf{5}$, view along $a$ axis with van Der Waals interactions.

Structures 7 and 11 contain solvent of crystallization but weak van Der Waals contacts dominate packing of these structures as well. In 7 the acetone molecules are interacting with the cobaltabisdicarbollides with very weak H-bonds between the acetone oxygen and carbon atoms of the carborane units (C-O heavy atom distances range from 3.224(4) to 3.489(4) $\AA$ ). Furthermore, in 7 the two cobaltabisdicarbollide units are linked together only by weak interactions forming 1D-chains. The $4,4^{\prime}$-pyridine rings of the neighbouring molecules are stacked but there are no strong $\pi$-contacts between the aromatic rings. The neighbouring units are connected via $\mathrm{CH} \cdots \mathrm{N}$ hydrogen bonds $(\mathrm{C} \cdots \mathrm{N}$ distances 3.270(5)-3.278(5) A) giving helical chains (Figure 7a)). Together the two closest chains form a double helix-like structure (Figure $7 \mathrm{~b}$ and S.I. Figure S. 4).

a)

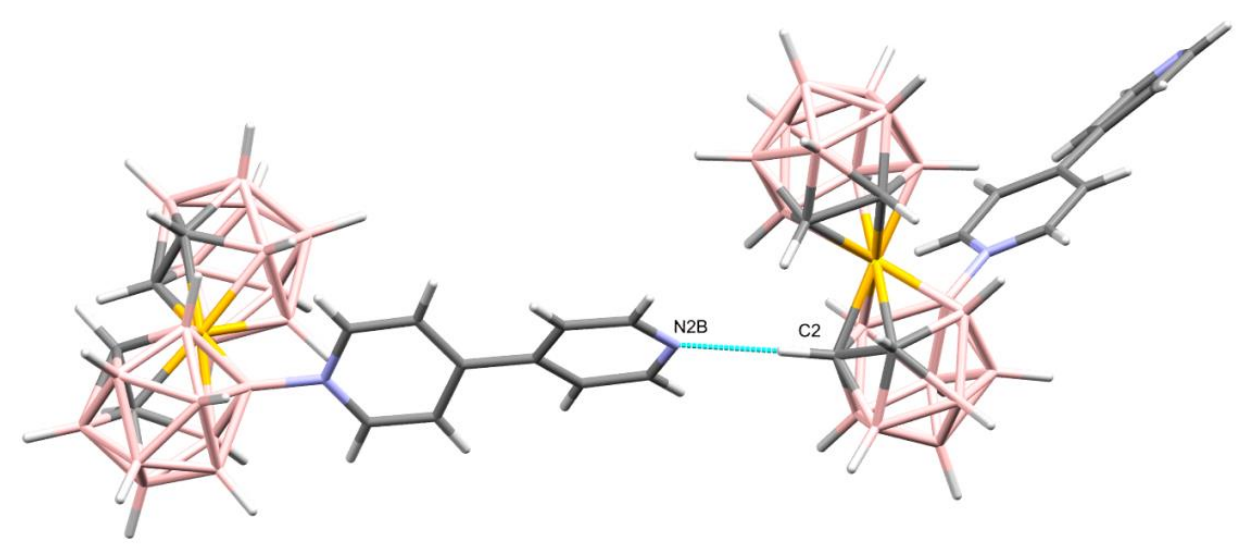


b)

Figure 7. a) Compound 7 displaying the pyr(N) $\cdots H-C_{c}$ interaction that forms $1 \mathrm{D}$-chain. b) Packing the two closest chains of 7 along $b$ axis form a double helix-like structure with van Der Waals interactions shorter than sum of vdW radii $-0.55 \AA$.

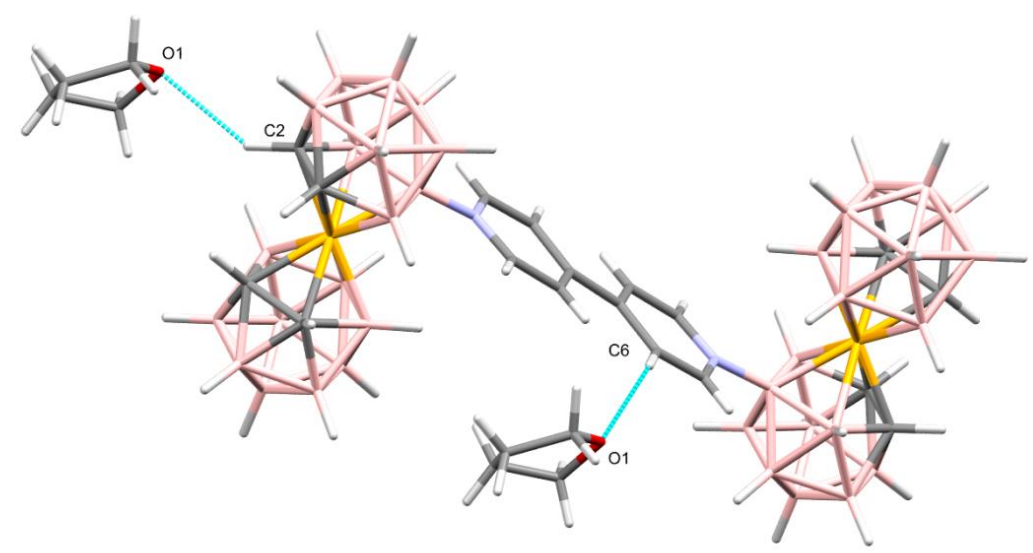

Figure 8. Interactions of a THF molecule with the pyridine hydrogens by means of $\mathrm{O} \cdots \mathrm{H}-\mathrm{C}_{\mathrm{pyr}}$ and a second one to the metallacarborane through a $\mathrm{O} \cdots \mathrm{H}-\mathrm{C}_{\mathrm{c}}$ hydrogen bond in compound $\mathbf{1 1}$.

The THF molecule in structure $\mathbf{1 1}$ is hydrogen bonded to the pyridine hydrogens and to one of the

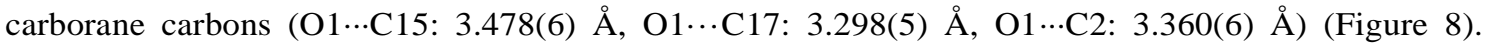
Relevant to the electronic communication, see later, between the two metal sites is the co-planarity of both pyridine units. In 7 there is no metal to metal communication because there is not a second metal in the molecule, and the torsional angle between the two pyridine units is $-20.24^{\circ}$; conversely in $\mathbf{1 1}$ this angle is $0.08^{\circ}$ meaning that the two pyridine units are coplanar (Figure 5), promoting therefore $\mathrm{M}$ to $\mathrm{M}$ electronic communication. The role of this coplanarity will be discussed later on this paper. In the case of the $\mathrm{Fe}$ metallacarboranes, the $\mathrm{Fe}^{3+}$ is paramagnetic, making difficult therefore their characterization by NMR. Their ${ }^{1} \mathrm{H}-\mathrm{NMR}$ are difficult to be analyzed, particularly the resonances of the bipyridine unit; instead, the ${ }^{11} \mathrm{~B}\left\{{ }^{1} \mathrm{H}\right\}$-NMR is very helpful to follow the progress of the reaction because the peak at $520 \mathrm{ppm}$, characteristic of the B-I vertex, is shifted up field near $-586 \mathrm{ppm}$ upon the formation of the $\mathrm{B}-\mathrm{N}$ bond. However, the ${ }^{11} \mathrm{~B}\left\{{ }^{1} \mathrm{H}\right\}-\mathrm{NMR}$ does not specify whether the semi(ferrabisdicarboranyl)viologen $(\mathbf{8})$ or the FeFe-homodi(metallacarboranyl)viologen (12) is produced. This information was retrieved after the $\mathrm{CV}$ was performed (See Electrochemical wave analysis section below). In the case of the heterodisubsituted CoFe compound, $\mathbf{1 3}$, the ${ }^{11} \mathrm{~B}\left\{{ }^{1} \mathrm{H}\right\}-\mathrm{NMR}$ is 
complex due to the presence of the paramagnetic $\mathrm{Fe}^{3+}$, which only affects half of the molecule. Once the ${ }^{11} \mathrm{~B}\left\{{ }^{1} \mathrm{H}\right\}$-NMR is analysed in detail, it is observed that by overlapping the ${ }^{11} \mathrm{~B}\left\{{ }^{1} \mathrm{H}\right\}$-NMR spectra of $\mathbf{7}$ and $\mathbf{8}$ the complex ${ }^{11} \mathrm{~B}-\mathrm{NMR}$ spectrum of $\mathbf{1 3}$ is generated (Figure 9). ${ }^{43,48-49}$ The ${ }^{11} \mathrm{~B}\left\{{ }^{1} \mathrm{H}\right\}$-NMR peaks at $-586 \mathrm{ppm}$ in compound $\mathbf{1 1}$ and at $+15 \mathrm{ppm}$ in $\mathbf{1 2}$ are indicative of the formation of the B-N bond between the bipyridine ferrabisdicarbollide and cobaltabisdicarbollide units, respectively. Moreover, all peaks common in both compounds appear in the heterobimetallic compound $\mathbf{1 3}$.

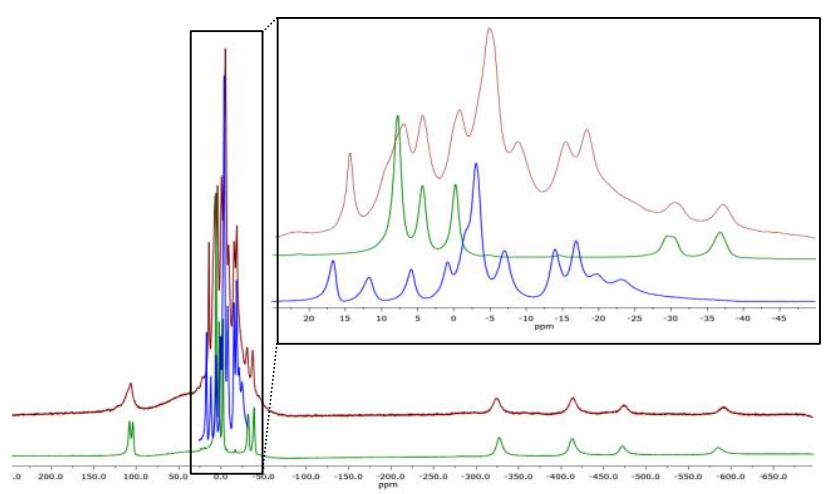

Figure 9. Overlapping of the ${ }^{11} \mathrm{~B}\left\{{ }^{1} \mathrm{H}\right\}$-NMR of compounds $\mathbf{7}$ (blue), $\mathbf{8}$ (green) and $\mathbf{1 3}$ (red).

\section{Electrochemical wave analysis}

Inspection of the $\mathrm{CV}$ of $\mathbf{1 3}$ or $\mathbf{1 1}$ in the potential range 0 to -1.8 displays 4 reversible $\mathrm{CV}$ waves at $0.34,-1.15,-1.47$ and $-1.78(\mathbf{1 3})$ and at $-0.99,-1.40,-1.53$ and $-1.79(\mathbf{1 1})$ as seen in Figure 10 , and Table 1. Its interpretation is not straightforward on the basis of [1] $]^{-}$and $[2]^{-}, \mathbf{7}$ and $\mathbf{8}$ and the $[\mathrm{MV}]^{2+}$, see again Table 1. For its full electrochemical wave' assignments, it was necessary to interpret all the set of compounds described in this work.

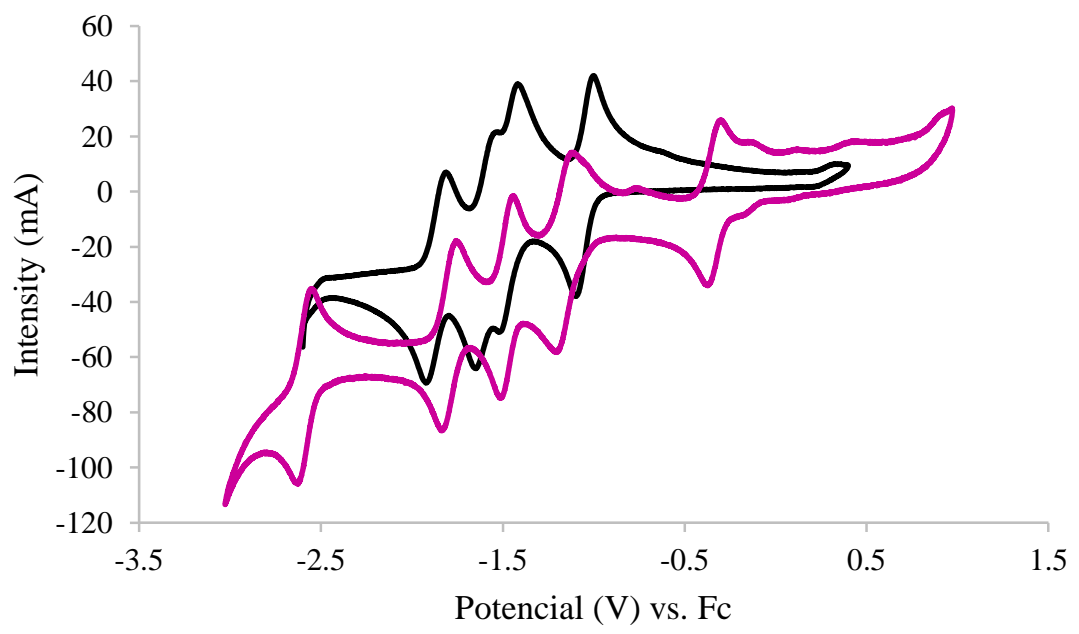

Figure 10. In black, the CV of compound 11, four waves are observed. In violet, $\mathrm{CV}$ of compound 13, five reversible waves are observed.

The CV analyses of the zwitterion pyridine derivatives $5(\mathrm{Co})$ and $\mathbf{6}(\mathrm{Fe})$ provide information about $\mathrm{E}_{1 / 2}$ when moving from one anion ([1 $]^{-}$or $[2]^{-}$, whose $\mathrm{E}_{1 / 2}$ are -1.74 and $-0.78 \mathrm{~V},{ }^{21}$ respectively) to the very similar but neutral compound ( 5 or $\mathbf{6}$ ) that causes a shift in the redox potential that is near to $+0.40 \mathrm{~V}$ 


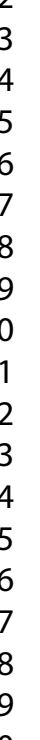

(Figure 11). This information enables to assign the peaks of $\mathbf{7}$ and $\mathbf{8}$, taking into account that these are also zwitterions, and the $\mathrm{E}_{1 / 2}$ of the central metal ion (Co or $\mathrm{Fe}$ ) is expected to be very similar to those of 5 and 6. In the CVs of $\mathbf{7}$ and $\mathbf{8}$, there are two additional peaks, one for each nitrogen of the bipyridine, one of them being formally positively charged shown as $\operatorname{Pyr}(+)$ in Table 1, and the second one neutral, shown as Pyr in Table 1; it was then easy to assume that the easiest in being reduced is the positively charged with $\mathrm{E}_{1 / 2}-1.75 \mathrm{~V}$ while the reduction of the neutral nitrogen appears at $-2.25 \mathrm{~V}$.

Table 1. $\mathrm{E}_{1 / 2}$ values and assignments of the $\mathrm{CV}$ waves $\left(\mathrm{vs} . \mathrm{Fc}^{+} / \mathrm{Fc}\right.$ ) for all synthesized compounds and free methylviologen (MV). The symbols in italics indicate the fragment to which is ascribed the redox process.

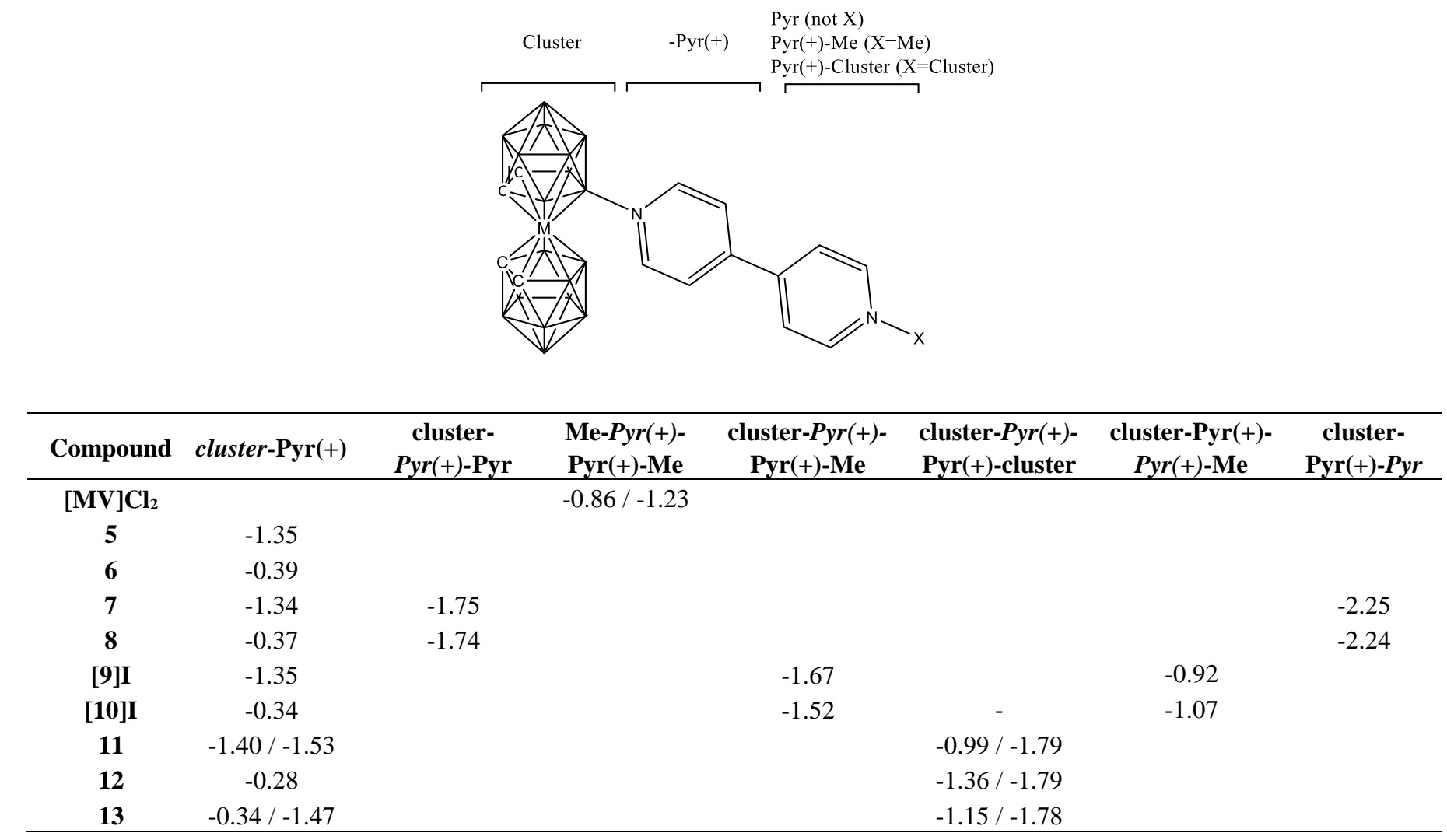

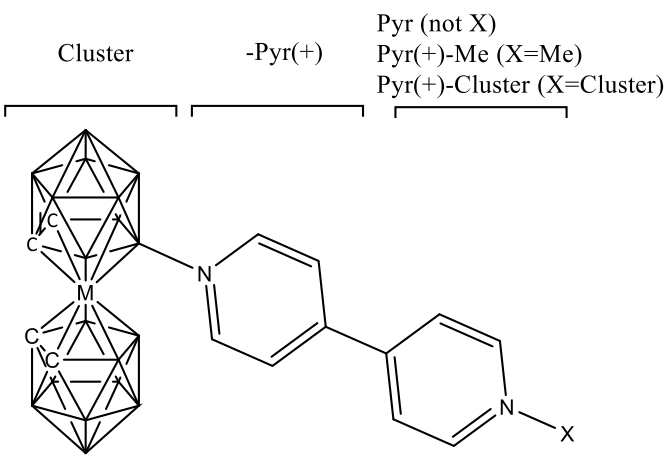



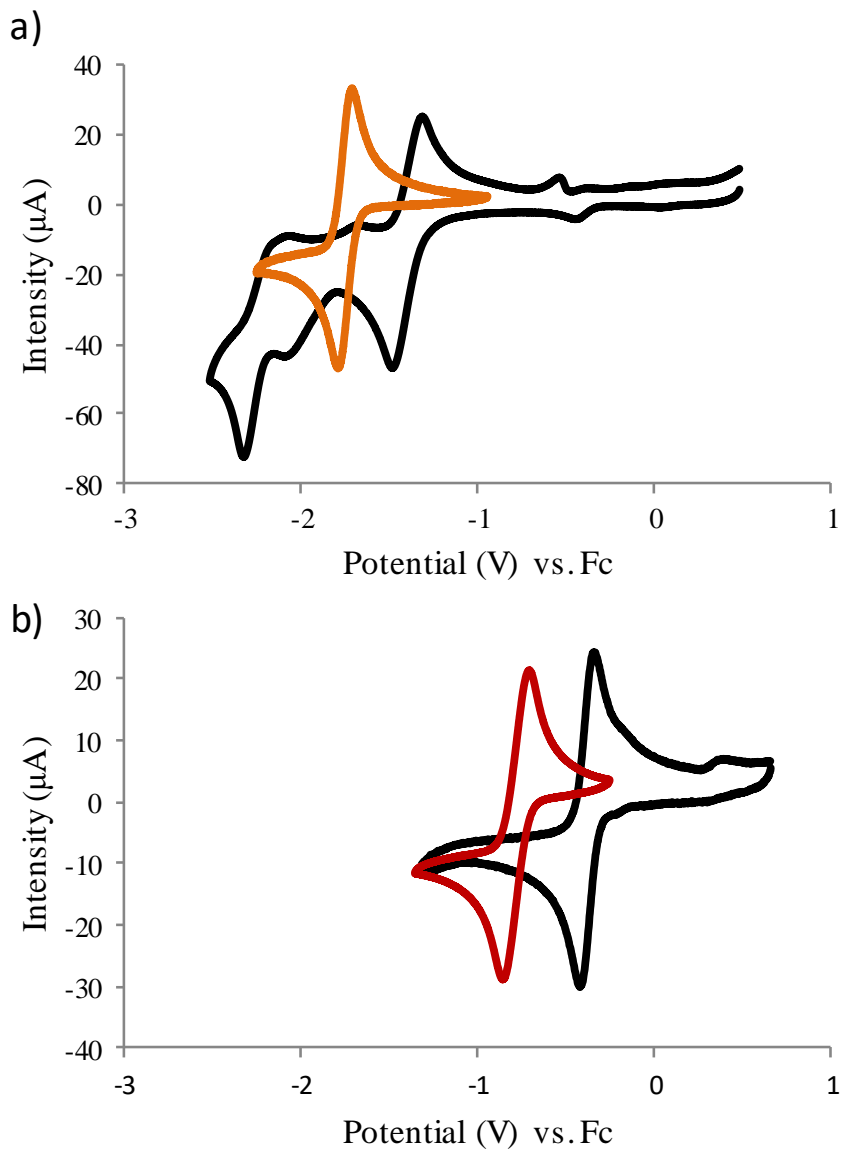

Figure 11. a) The CV of [1] $]^{-}$and 5 in orange and in black, respectively. b) The CV of [2]- (in red) and 6 (in black).

Compound [9]I differs from 7 just in one methyl group on the formerly free nitrogen of the bipyridine in 7. Three peaks are observed in the CV of [9]I, and comparing the CVs of [9]I and 7 it is seen that the peak at $-2.25 \mathrm{~V}$ in 7 is not present in [9]I, while one at $-0.92 \mathrm{~V}$ in [9]I appears, whereas the other two peaks remain at the same region. It can then be assumed that $\mathrm{E}_{1 / 2}$ for the $\mathrm{Me}-\mathbf{P y r}^{+}-\mathrm{Pyr}^{+}-$ $\mathrm{Co}\left(\mathrm{C}_{4} \mathrm{~B}_{18} \mathrm{H}_{21}\right)$ has a value of $-0.92 \mathrm{~V}$, similar to this for $[\mathrm{MV}]^{2+}$ that is $-0.86 \mathrm{~V}$. A similar interpretation can be given when comparing the CVs of $\mathbf{8}$ and [10]I, in which the new peak that appears at -1.07 is assigned to the methylated pyridine, because the other two peaks remain almost constant. Compound 12 was easily assigned because the $\mathrm{E}_{\frac{1}{2} / 2}$ of the $\mathrm{Fe}^{3+/ 2+}$ is twice more intense than the other two redox processes, indicating that both ferrabisdicarbollide units are reduced at the same time. On the contrary, the assignment of the redox processes for $\mathbf{1 1}$ was not as straightforward as for 12. In this case, there are two peaks at very similar potentials to [9]I, and therefore are assigned to the peaks for the reduction of both positive pyridine units, while the other two peaks, are assigned to a stepwise reduction of the two cobaltabisdicarbollide units with a $\Delta \mathrm{E}_{1 / 2}$ of $130 \mathrm{mV}$. This result was a definite indication of an electronic communication between the two cobaltabisdicarbollide units, which could suggest and confirm that there is a mixed valence compound. This electronic communication occurs because the two pyridine units of the bipyridine bridge are coplanar (Figure 5). Contrarily, in 12, the two-fold peak at $-0.28 \mathrm{~V}$ suggests but not confirms that there is no electronic communication between the two 
ferrabisdicarbollide units in agreement with the non-coplanarity of the two pyridine rings, as shown in the crystal structure of $\mathbf{1 2}$ (Figure 5). ${ }^{50}$

Finally, the assignment of the CV peaks for 13, was easily done on the bases of the former assignments. The more anodic peak at $-0.34 \mathrm{~V}$ corresponds to the $\mathrm{Fe}^{3+/ 2+}$ redox process, followed by the reduction of one of the pyridinium units at $-1.15 \mathrm{~V}$, that is in turn followed by the $\mathrm{Co}^{3+/ 2+}$ reduction at $-1.47 \mathrm{~V}$ and finally by the second pyridinium unit at $-1.78 \mathrm{~V}$ as it was expected. This data may suggest that some degree of electronic communication may exist between the two metallacarboranes. Unfortunately, we have not succeeded in getting good crystals that could unambiguously prove the coplanarity of the bipyridine bridge.

\section{Electronic communication}

The electronic communication between the two metal atoms in the [Co-Co] homodi(metallacarboranyl)viologen (11) was clearly established when two distinct $1 \mathrm{e}^{-}$curves were found for two chemically equivalent Co atoms that after ET became non-equivalent with a $\Delta \mathrm{E}_{1 / 2}$ of 130 $\mathrm{mV}$.

However the electronic communication apparently was non-existent for [Fe-Fe] homodi(metallacarboranyl)viologen (12) for which the $\Delta \mathrm{E}_{1 / 2}$ is 0 or near $0 \mathrm{mV}$. To solve this riddle, the following experiment was performed. A fresh solution of sodium naphthalenide was prepared mixing a solution of naphthalene in THF with metallic sodium under nitrogen. After few minutes, with vigorous stirring, the solution became dark green. After all sodium had reacted, the solution was titrated in water, with $\mathrm{HCl} 0.1 \mathrm{~N}$ standard solution. Then, a NMR tube with a known concentration of 12 in THF and 1 eq of sodium naphthalenide was prepared to perform a monoreduction of one of the two iron centers. The tube was sealed under nitrogen and the ${ }^{11} \mathrm{~B}\left\{{ }^{1} \mathrm{H}\right\}$-NMR was run at different temperatures (Figure 12). From the NMR, the following two conclusions can be drawn: first there is a shifting of the outer peaks towards the center of the spectrum due to the monoreduction and second, that after monoreduction of $\mathbf{1 2}$ there is not a dependence of the peak position with the temperature.

The first conclusion drawn from Figure 12, in which the peripheral peaks shift towards the centre of the unperturbed ${ }^{11} \mathrm{~B}\left\{{ }^{1} \mathrm{H}\right\}-\mathrm{NMR}$ spectrum, is that the singly reduced $[\mathrm{Fe}-\mathrm{Fe}]^{-}$molecule cannot be interpreted as a fix charge site complex of the type $\left[\mathrm{Fe}^{2+}-\mathrm{Fe}^{3+}\right]-$ but by a rapidly exchanging $\left[\mathrm{Fe}^{2+}-\mathrm{Fe}^{3+}\right]^{-}$ $\leftrightarrow\left[\mathrm{Fe}^{3+}-\mathrm{Fe}^{2+}\right]^{-}$system in which the oxidation states of the $\mathrm{Fe}$ are constantly interconverting due to a fast inner electron transfer (Intervalence Charge Transfer, IVCT). This fast interconversion leads to an intermediate species in which formally there are two $\mathrm{Fe}^{2.5+}$. This implies that the resulting NMR would be an intermediate between the paramagnetic NMR (two $\mathrm{Fe}^{3+}$ ) and the diamagnetic NMR (two $\mathrm{Fe}^{2+}$ ). If there was no electronic communication between both ferrabisdicarbollide units, the ${ }^{11} \mathrm{~B}\left\{{ }^{1} \mathrm{H}\right\}$-NMR peaks would be the sum of the paramagnetic NMR and the diamagnetic NMR in similarity with the ${ }^{11} \mathrm{~B}\left\{{ }^{1} \mathrm{H}\right\}-\mathrm{NMR}$ of $\mathbf{1 3}[\mathrm{Fe}-\mathrm{Co}]$ that has one diamagnetic center (the $\mathrm{Co}$ ) and one paramagnetic one (the $\mathrm{Fe})$. The second conclusion is the observed non-dependence of the ${ }^{11} \mathrm{~B}\left\{{ }^{1} \mathrm{H}\right\}$-NMR with the temperature indicating that the rate of the intervalence charge transfer is fast between the NMR at $290 \mathrm{~K}$ and the NMR at $213 \mathrm{~K}$. 
Figure 12. In red, the ${ }^{11} \mathrm{~B}\left\{{ }^{1} \mathrm{H}\right\}-\mathrm{NMR}$ of $\mathbf{1 2}$. On $2^{\text {nd }}$ place, the ${ }^{11} \mathrm{~B}\left\{{ }^{1} \mathrm{H}\right\}-\mathrm{NMR}$ of $[\mathbf{1 2}]$ at $290 \mathrm{~K}$, and subsequently the ${ }^{11} \mathrm{~B}\left\{{ }^{1} \mathrm{H}\right\}$-NMR of $[\mathbf{1 2}]^{-}$, decreasing the temperature $20 \mathrm{~K}$ between each NMR. Orange dotted lines indicate the shift of the ${ }^{11} \mathrm{~B}\left\{{ }^{1} \mathrm{H}\right\}$-NMR between compound 12 and [12]- The blue dotted lines show how the peaks are independent of the temperature. The large bump between +75 and -75 is due to the ${ }^{11} \mathrm{~B}\left\{{ }^{1} \mathrm{H}\right\}$-NMR signals inherent to the NMR tube that contains boron oxides. The fine signals on the bump are due to the boron atoms in the clusters.

To demonstrate this intervalence charge transfer, we run the UV-vis-NIR spectroscopy for compound 12 and $[12]^{-}$. For comparison, we have also run the UV-vis-NIR of compound 6 and $[6]^{-}$. As it is shown in Figure 13, the broad band with a maximum wavelength at $708 \mathrm{~nm}$ and expanding to the NIR region until $1250 \mathrm{~nm}$ is associated with an IVCT or also known as a metal to metal charge transfer, demonstrating again the electronic communication between the two metal centers of the molecule through the bipyridine moiety.

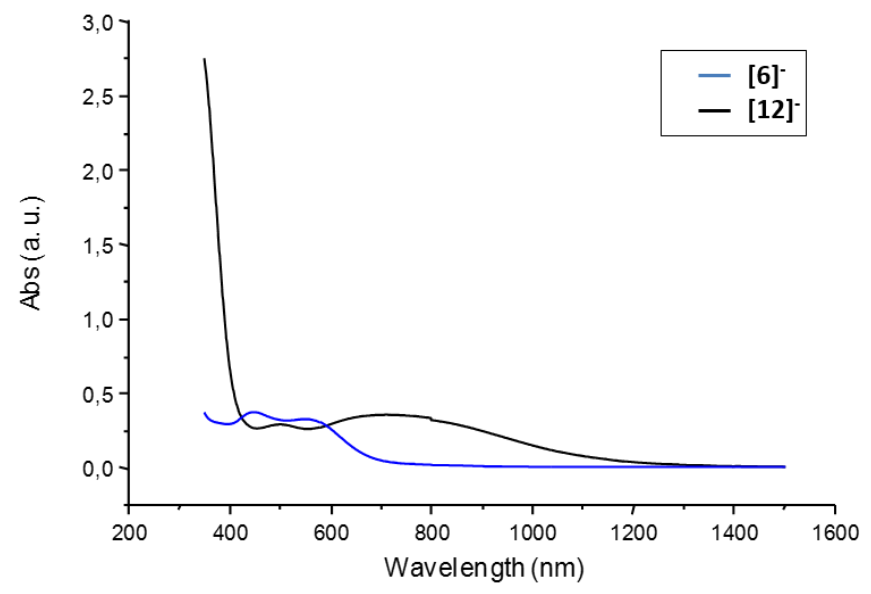

Figure 13. UV-vis-NIR of compounds [6]- (in blue) and [12]- (in black).

\section{Electron transfer}

The ability of these semi-, homo or heterodi(metallacarboranyl)viologens to accept electrons has been described in previous sections of this manuscript; depending on the molecule up to 5 electrons can be accepted in a reversible way under cyclic voltammetry conditions, as is the case for 13. Earlier, we 
have only dealt with 4 electrons, but as seen in Figure 10 , a $5^{\text {th }}$ also reversible peak near $-2.5 \mathrm{~V}$ is observed that is due to $\mathrm{Co}^{2+/+}$ couple. In this section, we wish to demonstrate the capacity of the di(metallacarboranyl)viologen compounds to transfer one accepted electron to a similar non reduced di(metallacarboranyl)viologen molecule. To demonstrate it, we made use of two physically and geometrically similar di(metallacarboranyl)viologen molecules: 11 ([Co-Co]) and $\mathbf{1 2}$ ([Fe-Fe]), taking advantage of the more anodic $\mathrm{E}_{1 / 2}$ value of $\mathbf{1 2}$, and the great ${ }^{11} \mathrm{~B}-\mathrm{NMR}$ difference between $\left[\mathrm{Fe}^{\mathrm{III}}-\mathrm{Fe}^{\mathrm{III}}\right]$, and $\left[\mathrm{Fe}^{\mathrm{III}}-\mathrm{Fe}^{\mathrm{II}}\right]^{-}$, that should permit to track clearly the destination of the transferred electron.

To do this, monoreduction of $\mathbf{1 1}$ was necessary, and this needed to be confirmed. To do so we did an EPR of a $10^{-2} \mathrm{M}$ solution of $\mathrm{Na}[\mathbf{1 1}]$ that was prepared by mixing 1 equivalent of sodiumnaphthalenide with 11. In Figure 14, the EPR spectra of sodium naphthalenide (black trace) and 11 (blue trace) are shown. The two EPR are distinct, with different g-factors and separations between peaks. For the sodium naphthalenide a g-factor of 2.00234 was obtained while for [11 $]^{-}$it was 2.00406 .

The separation between peaks is even more noteworthy, $5.66 \mathrm{G}$ for sodium naphthalenide and $18.6 \mathrm{G}$ for $[\mathbf{1 1}]^{-}$. Once the di(metallacarboranyl)viologen (11) could be loaded with one electron from a reducing agent, we moved to demonstrate that this electron could be ET to a similar molecule, another di(metallacarboranyl)viologen that for convenience, as indicated above, was taken $\mathbf{1 2}$.

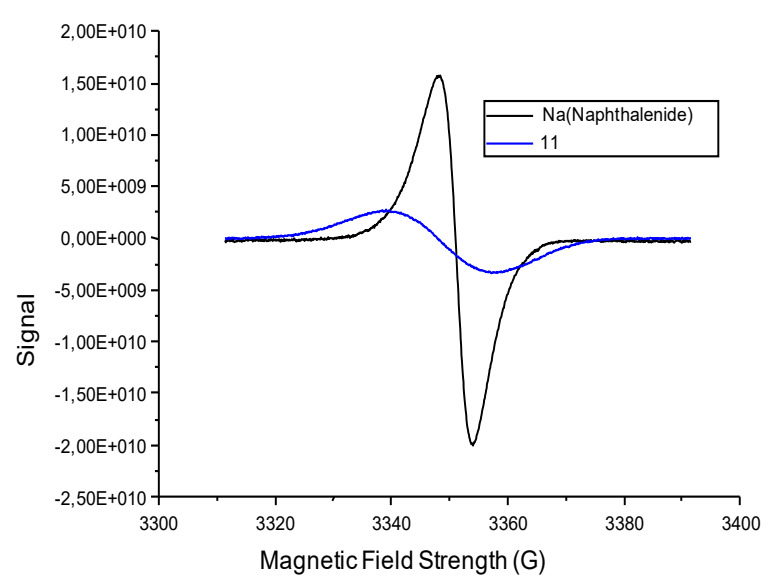

Figure 14. In black, the EPR spectrum of Sodium Naphthalenide, in blue, the EPR spectrum of compound [11].

To demonstrate this electron transfer, 1 equivalent of 12 was added to pre-form $[\mathbf{1 1}]^{-}$. The ${ }^{11} \mathrm{~B}\left\{{ }^{1} \mathrm{H}\right\}$ NMR (Figure 15) of the mixture was analysed observing that the ${ }^{11} \mathrm{~B}\left\{{ }^{1} \mathrm{H}\right\}-\mathrm{NMR}$ of compound 12, shown at the bottom in Figure 15, was not observed after adding 12 on [11 $]^{-}$that implies its reduction to $[12]^{-}$. 
With this experiment we have proven that the electron first went from the sodium naphthalenide to 11 producing the monoreduction of the compound, and then it did move from $[\mathbf{1 1}]^{-}$to 12. All this demonstrates the electron accepting capacity of these di(metallacarboranyl)viologen compounds along with their capacity to be donors, too.

\section{Self-assembly property}

In the former sections it has been shown the capacity of electron transfer between metallacarboranes in solution. For an adequate electron transfer, it is convenient having the donor and acceptor in a short distance. To see how these metallacarboranes pack in solid state the following experiments leading to learn on their capacity to self-assemble have been conducted. If self-assembling occurs, this certainly would facilitate producing wires, sheets or tri-dimensional arrays. As we have described in the introduction, metallacarboranes of the type $\left[3,3^{\prime}-\mathrm{Co}\left(1,2-\mathrm{C}_{2} \mathrm{~B}_{9} \mathrm{H}_{11}\right)_{2}\right]^{-}$have been demonstrated to selfassemble in water producing monolayer vesicles and micelles ${ }^{49,50-55}$ or, in the case of $[3,3$ '-Co(8-I-1,2$\left.\left.\mathrm{C}_{2} \mathrm{~B}_{9} \mathrm{H}_{10}\right)_{2}\right]^{-}$lamellae. ${ }^{51-57}$ These metallacarboranes are main parts of the di(metallacarboranyl)viologen compounds described and we foresee that they will self-assemble.

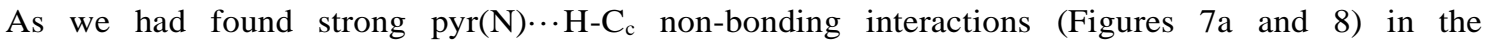
metallacarboranylviologen crystal structure of compounds $\mathbf{7}$ and 11, we hypothesized that such molecules could self-assemble to form supramolecular structures on a surface. Indeed this hypothesis turned to be correct and has permitted us investigating the resulting crystallites by atomic force microscopy (AFM) techniques.

By using the organic molecular beam deposition technique (OMBD) (see experimental section at S.I.) for the deposition under ultra-high vacuum (UHV) conditions different self-assembled structures were obtained on silicon substrates. The silicon surface (with native oxide on top, $\mathrm{SiO}_{2} / \mathrm{Si}$ ) was chosen because of its low surface roughness $(\leq 0.3 \mathrm{~nm})$ and easy preparation. The deposition parameters (rate and temperature) were varied in order to investigate their impact in the molecular self-assembly process. Thus, for substrate temperatures ranging from room temperature to $\sim 60^{\circ} \mathrm{C}$, regular micellelike structures were formed (see Figure S.21 in S. I.). Conversely, by choosing a substrate temperature 
of around $100^{\circ} \mathrm{C}$ crystallization of 7 was clearly observed. An example of such a crystalline structure is shown in the AFM topographic image presented in Figure 16. Though larger crystals were also found (see Figure S.22 in S. I.), in this particular case, the crystal is $\approx 7 \mathrm{~nm}$ in total height and several hundreds of nanometers in lateral dimensions.

The 3D crystal shown in Figure 16a consists of a large and atomically flat layer in contact with the substrate surface with a series of smaller terraces on top, separated by well-defined steps (see the high magnification image in the figure inset). As it can be extracted from the line profile in Figure $16 \mathrm{~b}$, the first layer is $\sim 2.7 \mathrm{~nm}$ in height.

Unequivocal demonstration of molecular self-assembly, for 7, is shown in Figure 16d. The structural detail of the supramolecular order existing on each molecular plane was gained by high resolution lateral force microscopy (also known as friction force microscopy, FFM) (see S. I.). The lattice resolved images obtained on top of every terrace of the crystal shown in Figure 16a presented the same hexagonal packing. Figure 16d and Figure 16e show the molecular periodicity FFM image (each feature in the lattice belonging to a molecular site) and the corresponding fast Fourier transform (FFT), respectively. The determined in-plane hexagonal lattice parameter of $\sim 0.5 \mathrm{~nm}$ fits reasonably well with the $\sim 0.6 \mathrm{~nm}$ semiaxis length of the cobaltabisdicarbollide groups in a $2 \mathrm{D}$ close-packed structure]. ${ }^{21}$ Interestingly, in addition to the central hexagon in Figure 16e ascribed to the $2 \mathrm{D}$ hexagonal lattice observed in Figure 16d, some extra points are distributed along the FFT diagonal. Far from being an artifact, these points arise from the structural asymmetry of the 7-compound due to the lateral bipyridine unit, which breaks the symmetry plane of the supramolecular packing and appears as the brighter edge of each molecular feature in Figure 16d and AFM image in Figure S.23 of S. I.

In resume, our AFM results are compatible with the formation of molecular crystals of 7 on the $\mathrm{SiO}_{2} / \mathrm{Si}$ surface in which the molecules assemble themselves in a hexagonal closed-packed 3D crystal structure (either hcp or fcc) consisting of 2D hexagonal molecular planes (in plane lattice parameter a $\approx 0.5 \mathrm{~nm}$ ) with the molecules main axis tilted out of the vertical crystallographic axis so that the interlayer distance is $\mathrm{h} \approx 0.9 \mathrm{~nm}$ (see hcp model of Figure S23 in S. I.). 
Figure 16. (a) AFM topographic image of 7 crystal structures on top of a $\mathrm{SiO}_{2} / \mathrm{Si}$ surface. The image lateral size is $1 \mu \mathrm{m} \times 1 \mu \mathrm{m}$ and the total $\mathrm{z}$-scale is $20 \mathrm{~nm}$. Inset: magnification of the square region $(200 \mathrm{~nm} \times 200 \mathrm{~nm})$. (b) Relief profile taken along the dashed segment indicated in (a). (c) Height histogram of an area including crystallite and bare substrate surface in (a). (d) High resolution molecular periodicity image obtained on top the crystal by AFM in the lateral force measuring mode. (e) FFT image corresponding to (d). All AFM images are non-filtered raw data.

\section{Solubility and Processability.}

Following the synthetic development with emphasis in producing high yields in a single or two stages procedure, the characterization study, the thermal and air stability, the electron accepting capacity along with the electron donor ability, the capacity to accumulate electrons, the redox potential tunability, and the self-assembling capacity of the di(metallacarboranyl)viologen compounds described in this work, and considering their potential applications in molecular electronics, solar cells or any other process where electron storage and release are paramount, one of the most important factors for their possible application is that they need to be easily processed. Thus we proceeded to study their solubility in a diverse set of solvents, and we have paid particular attention for 11, taking it as a model compound. To measure its solubility, the UV/Vis spectroscopy has been used to prepare the calibration curve in each solvent (See S.I.). Then a saturated solution of the compound in each solvent was prepared from which a dilution was made to make it fit in the calibration curve. Six different representative solvents have been used: acetonitrile, dichloromethane, ethanol, tetrahydrofuran, toluene, and N,N-dimethylformamide. In SI all information leading to how to calculate the solubility values given in Table 2 is given.

In Table 2 are summarized the results of solubility in $\mathrm{mg} / \mathrm{mL}$ for compound $\mathbf{1 1}$ in each solvent, and are compared with the highly relevant for molecular electronics $\mathrm{C}_{60}$ and PCBM. Moreover, the solubility of compounds 12 and 13 has also been measured in acetonitrile, giving values of 52 and $44.6 \mathrm{mg} / \mathrm{mL}$ respectively, just for comparison and to prove that all compounds are very soluble in organic solvents. 


\section{Comparison between the physicochemical properties of $\mathrm{C}_{60}$ and 11}

To highlight the physico-chemical qualities of 11, particularly the electrochemical properties, ease of processability and stability in air and temperature, we considered that the most appropriate course of action would be to compare $\mathbf{1 1}$ with fullerene and fullerene derivatives that are widely used electron acceptors, particularly in bulk heterojunction solar cells. If we pay attention to the electrochemical properties the matching between the redox potentials of 11 and 12 with $\mathrm{C}_{60}$ or PCBM is very high. In this sense, it has been reported that the redox processes for $\mathrm{C}_{60}$ are $-1.10,-1.49$ and -1.94 and for PCBM -1.18, -1.55 and $-2.05 \mathrm{~V} v s$ Fc. ${ }^{60}$ Other values given for $\mathrm{C}_{60}$ are $-0.89,-1.37,-1.87,-2.35,-2.85$ and -3.26 (all values are reported vs external Ferrocene). ${ }^{61}$ As we have described previously in this work, the redox processes for compound 11 are $-0.99,-1.40,-1.53$ and -1.79 (all values are reported $v s$ external Ferrocene). Moreover, two more reversible redox processes are available at more cathodic values for the process $\mathrm{Co}^{+/ 2+}$. From $-0.5 \mathrm{~V}$ to $-2 \mathrm{~V}, \mathrm{C}_{60}$ is capable of accepting 3 electrons while 11 is capable of accepting 4. The same happens with 12, the difference being that in this case the values are even more anodic. Another positive aspect for these metallacarboranylviologen compounds is that $E_{1 / 2}$ fine tuning of the metallacarborane units can be achieved, thus adding an extra possibility to adapt the molecule to the targeted voltages. ${ }^{3}$

Concerning the solubility, the values shown in Table 2 indicate that the metallacarboranylviologen compounds are much more soluble than $\mathrm{C}_{60}$ and its derivatives in the same or much related solvents, but most importantly that they offer a wider range of solvents of different nature. The fact that these new compounds are very soluble in common organic solvents makes them possible candidates for molecular electronics and molecular materials in general.

\section{Conclusions}

A procedure leading to the formation of a B-N(aromatic) bond in a cluster has been developed. It consists of a parallel decomposition reaction to generate a reactive electrophile and a synthesis reaction to generate the $\mathrm{B}-\mathrm{N}$ bond. This has paved the way to produce the metallacarboranylviologen and semi(metallacarboranyl)viologen electron cumulative molecules with Fe, Co or a mix of both. These molecules are able to accept up to five electrons and to donate one in single electron steps at accessible potentials and in a reversible way. By targeted synthesis and corresponding electrochemical tests each ET step has been assigned to specific fragments of the molecules. The molecules have been carefully 
characterized and the electronic communication between both metal centers (when this situation applies) has been definitely observed through the co-planarity of both pyridine fragments. The structural characteristics of these molecules imply a low reorganization energy that is a requirement for low energy ET processes. This makes them electronically comparable to fullerenes, but with a wide range of possible solvents. The electronic transfer from one molecule to another has been clearly demonstrated as well as their self-organizing capacity. We consider that these molecules thanks to their easy synthesis, ET, self-organizing capacity, wide range of solubility and easy processability can find important application in any area where ET is paramount.

\section{Acknowledgements}

This work has been supported by the Spanish Ministerio de Economía y Competitividad (CTQ201675150-R) and Generalitat de Catalunya (2014/SGR/149). A. B. Buades is enrolled in the PhD program of UAB.

\section{Electronic Supplementary Information (ESI) available.}

The Supporting Information includes an experimental section with synthesis and full characterization of the reported compounds (Cs[3], Cs[4], 5 - 8, [9]I, [10]I, 11 - 13). Electrochemical studies of 5 - 13; UV-vis-NIR studies of 12, atomic Force Microscopy images of 7 and the crystallographic details of the 5- 8, 11 and 12 crystals (CCDC 1581998-1582000 for Co and 1582429-1582431 for Fe complexes, respectively). Their crystallographic data can be obtained free of charge via www.ccdc.cam.ac.uk/conts/retrieving.html (or from the Cambridge Crystallographic Data Centre, 12 Union Road, Cambridge CB2 1EZ, U.K.; fax: (+44) 1223336033; or e-mail: deposit@ccdc.cam.ac.uk). This material is available free of charge via the Internet at http://pubs.acs.org.

\section{Notes and references}

(1) Zhang, J. L.; Zhong, J. Q.; Lin, J. D.; Hu, W. P.; Wu, K.; Xu, G. Q.; Wee, A. T. S. Chem. Soc. Rev. 2015, 44, 2998-3022.

(2) Núñez, R.; Romero, I.; Teixidor, F.; Viñas, C. Chem. Soc. Rev. 2016, 45, 5147-5173.

(3) Núñez, R.; Tarrés, M.; Ferrer-Ugalde, A.; de Biani, F.; Teixidor, F. Chem. Rev. 2016, 116, 1430714378.

(4) Guldi, D. M. Chem. Commun. 2000, 321-327.

(5) Dresselhaus, M. S.; Dresselhaus, G.; Eklund, P. C., Chapter 20 - Applications of Carbon Nanostructures. In Science of Fullerenes and Carbon Nanotubes, Academic Press: San Diego, 1996; pp 870917.

(6) Stephens, P. W.; Mihaly, L.; Lee, P. L.; Whetten, R. L.; Huang, S.M.; Kaner, R.; Deiderich, F.; Holczer, K. Nature 1991, 351, 632-634.

(7) Tanaka, H.; Takeuchi, K. Appl. Phys. A-Mater 2005, 80, 759-761.

(8) Ammam, M. J. Mater. Chem. A 2013, 1, 6291-6312.

(9) Long, D.-L.; Burkholder, E.; Cronin, L. Chem. Soc. Rev. 2007, 36, 105-121.

(10) Busche, C.; Vila-Nadal, L.; Yan, J.; Miras, Haralampos N.; Long, D.-L.; Georgiev, V. P.; Asenov, A.; Pedersen, R. H.; Gadegaard, N.; Mirza, M. M.; Paul, Douglas J.; Poblet, J. M.; Cronin, L. Nature 2014, 515, 545-549.

(11) Ganesamoorthy, R.; Sathiyan, G.; Sakthivel, P. Sol. Energ. Mater. Sol. Cells 2017, 161, 102-148.

(12) Speller, E. M. Mater. Sci. Tech. 2017, 33, 924-933.

(13) Grimes, R. N., Carboranes ( $3^{\text {rd }}$ Edition). Academic Press,US, 2016.

(14) Hawthorne, F. M.; Andrews, T. D. Chem. Commun. 1965, 443-444.

(15) Hawthorne, F. M.; Young, D. C.; Andrews, T. D.; Howe, D. V.; Pilling, R. L.; Pitts, A. D.; Reintjes, M.; Warren, L. F.; Wegner, P. A. J. Am. Chem. Soc 1968, 90, 879-896. 
(17) Masalles, C.; Llop, J.; Viñas, C.; Teixidor, F. Adv. Mater. 2002, 14, 826-829.

(18) Brusselle, D.; Bauduin, P.; Girard, L.; Zaulet, A.; Viñas, C.; Teixidor, F.; Ly, I.; Diat, O. Angew. Chem. Inter. Ed. 2013, 52, 12194-12194.

(19) Fanning, J. C.; Huff, L. A.; Smith, W. A.; Terrell, A. S.; Yasinsac, L.; Todd, L. J.; Jasper, Steve A.; McCabe, D. J. Polyhedron 1995, 14, 2893-2900.

(20) Tarrés, M.; Viñas, C.; González-Cardoso, P.; Hänninen, M. M.; Sillanpää, R.; Ďord’ovič, V.; Uchman, M.; Teixidor, F.; Matějíček, P. Chem. Eur. J. 2014, 20, 6786-6794.

(21) Tarres, M.; Arderiu, Víctor S.; Zaulet, A.; Viñas, C.; Fabrizi de Biani, F.; Teixidor, F. Dalton Trans. 2015, 44, 11690-11695.

(22) Corsini, M.; Fabrizi de Biani, F.; Zanello, P. Coord. Chem. Rev. 2006, 250, 1351-1372.

(23) Poater, J.; Solà, M.; Viñas, C.; Teixidor, F. Angew. Chem. Inter. Ed. 2014, 53, 12191-12195.

(24) González-Cardoso, P.; Stoica, Anka-I.; Farràs, P.; Pepiol, A.; Viñas, C.; Teixidor, F. Chem. Eur. J. 2010, 16, 6660-6665.

(25) Pepiol, A.; Teixidor, F.; Sillanpää, R.; Lupu, M.; Viñas, C. Angew. Chem. Inter. Ed. 2011, 50, 1249112495.

(26) Mortimer, R. J. Electrochim. Acta 1999, 44, 2971-2981.

(27) Suzuki, M.; Morris, N. D.; Mallouk, T. E. Chem. Commun. 2002, 1534-1535.

(28) Grüner, B.; Kvíčalová, M.; Plešek, J.; Šícha, V.; Císařová, I.; Lučaníková, M.; Selucký, P. J. Organomet. Chem. 2009, 694, 1678-1689.

(29) Plesek, J.; Vangani V.; Fuse, J. Collect. Czech. Chem. Commun. 1994, 59, 1326-1336.

(30) Plesek, J.; Hermanek, S. Collect. Czech. Chem. Commun. 1984, 49, 1492-1496.

(31) Plesek, J.; Todd, L. J.; Wright, W.F. Collect. Czech. Chem. Commun. 1976, 41, 3509-3515.

(32) Olid, D.; Núñez, R.; Viñas, C.; Teixidor, F. Chem. Soc. Rev. 2013, 42, 3318-3336.

(33) Sícha, V.; Plesek, J.; Kvícalova, M.; Cisarova, M.; Grüner, B.; Dalton Trans. 2009, 851-860.

(34) Zakharkin, L. I.; Kalinin, V. N.; Gedymin, V. V. J. Organomet. Chem. 1969, 16, 371-379.

(35) Lupu, M.; Zaulet, A.; Teixidor, F.; Ruiz, E.; Viñas, C. Chem. Eur. J. 2015, 21, 6888-6897.

(36) Douvris, C.; Michl, J. Chem. Rev. 2013, 113, PR179-PR233.

(37) Mátel, L'.; Macášek, F.; Rajec, P.; Heřmánek, S.; Plešek, J. Polyhedron 1982, 1, 511-519.

(38) Crystal structure determination of complex 5: $\mathrm{C}_{9} \mathrm{H}_{26} \mathrm{~B}_{18} \mathrm{CoN}, \mathrm{M}=401.82$, monoclinic, $\mathrm{a}=6.9140(2)$, $\mathrm{b}=25.9050(5), \mathrm{c}=11.1660$ (4) $\AA, \beta=90.356 \mathrm{deg}, \mathrm{V}=1999.87(10) \AA^{3}, \mathrm{~T}=123 \mathrm{~K}$, space group P21/n (no.14), Z $=4,10785$ reflections measured, 3515 unique (Rint $=0.0528)$, which were used in all calculations. The final wR(F2) was 0.1192 (all data).

(39) Crystal structure determination of complex 6: Crystal data. $\mathrm{C}_{9} \mathrm{H}_{26} \mathrm{~B}_{18} \mathrm{Fe} \mathrm{N}, \mathrm{M}=398.74$, Monoclinic, a $=6.8607(17) \AA, b=52.326(12) \AA, c=11.328(3) \AA, \beta=90.658(5) \mathrm{deg}, \mathrm{V}=4066.5(17) \AA^{3}, \mathrm{~T}=100(2) \mathrm{K}$, space group $\mathrm{P} 21 / \mathrm{n}$ (no.11), $\mathrm{Z}=8,28073$ reflections measured, 9333 unique (Rint $=0.0821$ ), which were used in all calculations. The final wR(F2) was 0.1679 (all data).

(40) Crystal structure determination of complex 7: $\mathrm{C}_{17} \mathrm{H}_{35} \mathrm{~B}_{18} \mathrm{CoN}_{2} \mathrm{O}, \mathrm{M}=536.98$, Orthorhombic, $\mathrm{a}=$ 12.2131(2) $\AA \mathrm{b}=12.3627(2) \AA, \mathrm{c}=37.7627(7) \AA, \mathrm{V}=5701.67(19) \AA^{3}, \mathrm{~T}=120 \mathrm{~K}$, space group $\mathrm{P} 212121$ (no.19), $\mathrm{Z}=8,28104$ reflections measured, 13955 unique $(\mathrm{Rint}=0.0552)$, which were used in all calculations. The final wR(F2) was 0.0994 (all data).

Crystal structure determination of complex 8: $\mathrm{C}_{30} \mathrm{H}_{63} \mathrm{~B}_{36} \mathrm{Fe}_{2} \mathrm{~N}_{5} \mathrm{O}, \mathrm{M}=1010.71$, Monoclinic, $\mathrm{a}=12.295(6) \AA$, b $=11.814(6) \AA, c=18.592(12) \AA, \beta=99.332(10) \mathrm{deg}, \mathrm{V}=2665(3) \AA^{3}, \mathrm{~T}=100(2) \mathrm{K}$, space group Pc (no.7), $\mathrm{Z}$ $=2,32964$ reflections measured, 12527 unique (Rint $=0.0435)$, which were used in all calculations. The final wR(F2) was 0.1118 (all data).

Crystal structure determination of complex 11: $\mathrm{C}_{26} \mathrm{H}_{66} \mathrm{~B}_{36} \mathrm{Co}_{2} \mathrm{~N}_{2} \mathrm{O}_{2}, \mathrm{M}=945.82$, monoclinic, $\mathrm{a}=12.2514(4) \AA$, $\mathrm{b}=17.1579(5) \AA, \mathrm{c}=13.0272(4) \AA, \beta=114.8840(10) \mathrm{deg}, \mathrm{V}=2484.19(13) \AA^{3}, \mathrm{~T}=170 \mathrm{~K}$, space group P21/n (no.14), $\mathrm{Z}=2,25212$ reflections measured, 6672 unique $(\mathrm{Rint}=0.0687$ ), which were used in all calculations. The final $w R(F 2)$ was 0.1880 (all data).

Crystal structure determination of complex 12: $\mathrm{C}_{20} \mathrm{H}_{53} \mathrm{~B}_{36} \mathrm{Fe}_{2} \mathrm{~N}_{3}, \mathrm{M}=836.51$, Orthorhombic, $\mathrm{a}=13.293(9) \AA$, b $=24.939(17) \AA, c=25.915(17) \AA, V=8592(10) \AA^{3}, T=100(2) \mathrm{K}$, space group Pbca (no.61), $\mathrm{Z}=8,49719$ reflections measured, 9361 unique (Rint $=0.4326)$, which were used in all calculations. The final $w R(F 2)$ was 0.2798 (all data).

(41) Henisch, H. K., Crystals in Gels and Liesegang Rings. Cambridge University Press: New York, 1988.

(42) Rojo, I.; Teixidor, F.; Viñas, C.; Kivekäs, R.; Sillanpää, R. Chem. Eur. J. 2003, 9, 4311-4323.

(43) Farràs, P.; Teixidor, F.; Kivekäs, R.; Sillanpää, R.; Viñas, C.; Grüner, B.; Cisarova, I. Inorg. Chem. 2008, 47, 9497-9508.

(44) Llop, J.; Masalles, C.; Viñas, C.; Teixidor, F.; Sillanpää, R.; Kivekas, R. Dalton Trans. 2003, 4, 556-

561.

(45) Bruno, I. J.; Cole, J. C.; Edgington, P. R.; Kessler, M.; Macrae, C. F.; McCabe, P.; Pearson, J.; Taylor, R. Acta Cryst. Section B 2002, 58, 389-397.

(46) For Co: DOSJAX, DOSJIF, DOSJOL, DOSJUR in Sícha, V.; Plesek, J.; Kvícalov, M.; Císarova I.; Gruner. B. Dalton Trans., 2009, 851-860; HATRID in Císarová, I.; Malý K.; Hummel. L. Acta Cryst. 1994. 
C50, 198-200; IMEKOB in Bregadze, V. I.; Kosenko, I. D.; Lobanova, I. A.; Starikova, Z. A.; Godovikov, I. A.; Sivaev. I. B. J. Organomet. Chem. 2010, 29, 5366-5372; UNACIX in Kosenko, I.; Lobanova, I.; Ananyev, I.; Laskova, J.; Semioshkin, A.; Bregadze. V. J. Organomet. Chem. 2016, 818, 58-67.

(47) For Fe, KIWJIJ in Kang, H. C.; Lee, Sharon. S.; Knobler, C. B.; Hawthorne, M. F. Inorg. Chem. 1991, 30, 2024-2031.

(48) Farràs, P.; Cioran, A. M.; Šícha, V.; Teixidor, F.; Štíbr, B.; Grüner, B.; Viñas, C. Inorg. Chem. 2009, $48,8210-8219$.

(49) Cioran, A. M.; Teixidor, F.; Viñas, C. Dalton Trans. 2015, 44, 2809-2818.

(50) Benniston, A. C.; Harriman, A. Chem. Soc. Rev. 2006, 35, 169-179.

(51) Bauduin, P.; Prevost, S.; Farràs, P.; Teixidor, F.; Diat, O.; Zemb, T. Angew. Chem. Int. Ed. 2011, 50, 5298-5300.

(52) Ďord'ovič, V.; Tošner, Z.; Uchman, M.; Zhigunov, A.; Reza, M.; Ruokolainen, J.; Pramanik, G.; Cígler, P.; Kalíková, K.; Gradzielski, M.; Matějíček, P. Langmuir 2016, 32, 6713-6722.

(53) Chevrot, G.; Schurhammer, R.; Wipff, G. J. Phys. Chem. B 2006, 110, 9488-9498.

(54) Gassin, P. M.; Girard, L.; Martin-Gassin, G.; Brusselle, D.; Jonchère, A.; Diat, O.; Viñas, C.; Teixidor, F.; Bauduin, P. Langmuir 2015, 31, 2297-2303.

(55) Uchman, M.; Dord'ovič, V.; Tošner, Z.; Matějíček, P. Angew. Chem. Inter. Ed. 2015, 54, 1411314117.

(56) Hardie, M. J.; Raston, C. L. Chem. Commun. 2001, 10, 905-906.

(57) Viñas, C.; Tarrés, M.; Gonzalez-Cardoso, P.; Farràs, P.; Bauduin, P.; Teixidor, F. Dalton Trans. 2014, $43,5062-5068$.

(58) Semenov, K. N.; Charykov, N. A.; Keskinov, V. A.; Piartman, A. K.; Blokhin, A. A.; Kopyrin, A. A. J. Chem. Eng. Data 2010, 55, 13-36.

(59) Machui, F.; Langner, S.; Zhu, X.; Abbott, S.; Brabec, C. J. Sol. Energ. Mater. Sol. Cells 2012, 100, $138-146$

(60) Komatsu, K.; Takimoto, N.; Murata, Y.; Wan, T. S. M.; Wong, T. Tetrahedron Lett. 1996, 37, 61536156.

(61) Boudon, C.; Gisselbrecht, J.-P.; Gross, M.; Herrmann, A.; Rüttimann, M.; Crassous, J.; Cardullo, F.; Echegoyen, L.; Diederich, F. J. Am. Chem. Soc 1998, 120, 7860-7868. 


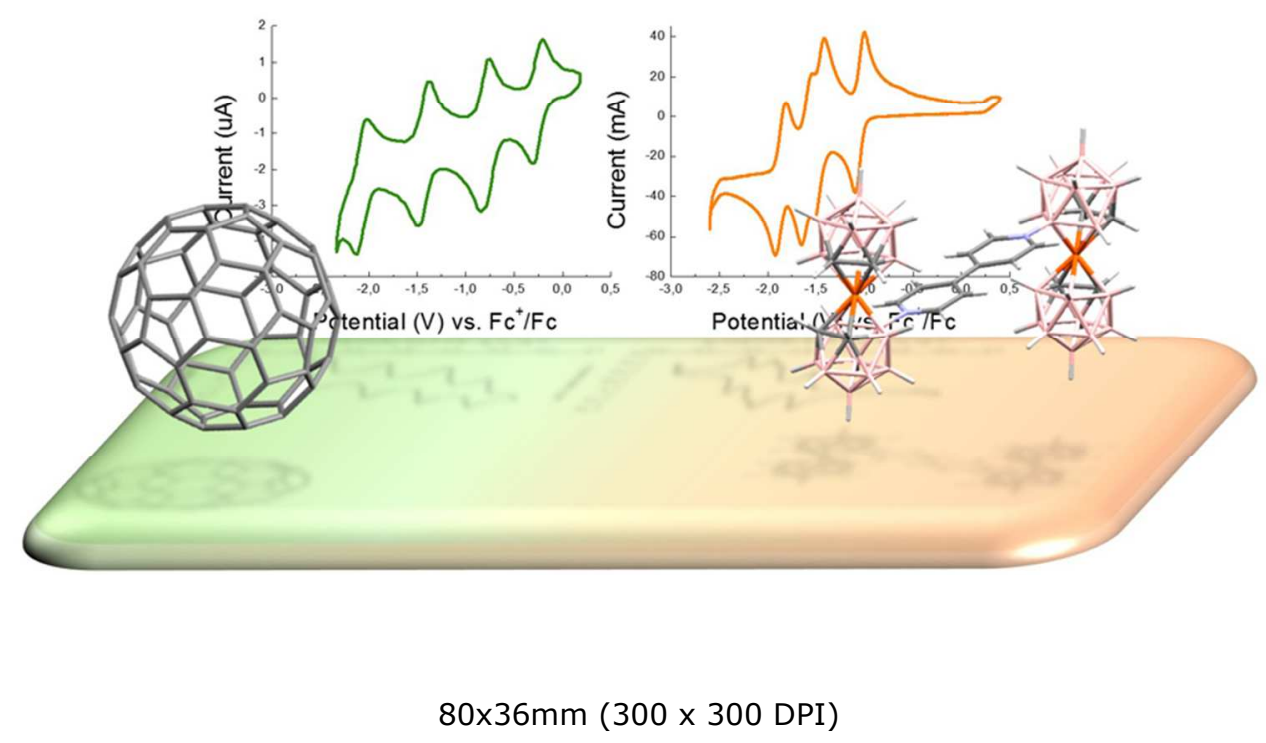

ACS Paragon Plus Environment 